Canadian Science Publishing

Canadian Journal of Earth Sciences Revue canadienne des sciences de la Terre

\title{
Seismic velocity model of the crust in the northern Canadian Cordillera from Rayleigh wave dispersion data
}

\begin{tabular}{|r|l|}
\hline Journal: & Canadian Journal of Earth Sciences \\
\hline Manuscript ID & cjes-2016-0115.R1 \\
\hline Manuscript Type: & Article \\
\hline Date Submitted by the Author: & 06-Sep-2016 \\
\hline Complete List of Authors: & $\begin{array}{l}\text { Ma, Shutian; University of Ottawa, Earth and Environmental Sciences } \\
\text { Audet, Pascal; University of Ottawa, Earth and Environmental Sciences }\end{array}$ \\
\hline Keyword: & Canadian Cordillera, Earth's crust, Rayleigh wave, Seismic velocity model \\
\hline & \\
\hline
\end{tabular}




\title{
Seismic velocity model of the crust in the northern Canadian Cordillera from Rayleigh
}

\section{wave dispersion data}

Shutian Ma and Pascal Audet*

Department of Earth and Environmental Sciences, University of Ottawa

*Corresponding author: pascal.audet@uottawa.ca

\begin{abstract}
Models of seismic velocity structure of the crust in the seismically active northern Canadian Cordillera remain poorly constrained, despite their importance in the accurate location and characterization of regional earthquakes. On 29 August 2014, a moderate earthquake with magnitude $M_{B} 5.0$ occurred in the Northwest Territories, Canada, $\sim 100 \mathrm{~km}$ to the east of the Cordilleran Deformation Front, which generated high-quality Rayleigh wave data. We carefully selected 23 seismic stations that recorded the Rayleigh waves and divided them into 13 groups according to the azimuth angle between the earthquake and the stations; these groups mostly sample the Cordillera. In each group, we measured Rayleigh wave group velocity dispersion, which we inverted for one-dimensional shear-wave velocity models of the crust. We thus obtained 13 models that consistently show low seismic velocities with respect to reference models, with a slow upper and lower crust surrounding a relatively fast mid crustal layer. The average of the 13 models is consistent with receiver function data in the central portion of the Cordillera. Finally, we compare earthquake locations determined by the Geological Survey of Canada using a simple homogenous crust over a mantle half space with those estimated using the new crustal velocity model, and show that estimates can differ by as much as $10 \mathrm{~km}$.
\end{abstract}


Keywords: Canadian Cordillera; Earth's crust; Rayleigh wave; Seismic velocity model

\section{Introduction}

The northern Canadian Cordillera (NCC) is one of the most tectonically and seismically active regions in Canada (Hyndman et al. 2005), and encompasses the entire Yukon Territory and the western part of the Northwest Territories. The NCC is separated from the adjacent Canadian Shield by an abrupt change in topography at the Cordilleran Deformation Front (Fig. 1). Within the NCC, several bands of seismicity roughly follow the NW-SE striking Denali and Tintina faults, and a more diffuse NW-SE trending band of seismicity cuts through the Mackenzie Mountains and follows the strike of the Deformation Front in the north.

This region is host to some of the largest continental earthquakes in Canada (Hyndman et al. 2005) and the highest seismicity rates. In 1985, two earthquakes of moment magnitude $\mathrm{M}_{\mathrm{W}} \sim 6.5$ and $\mathrm{M}_{\mathrm{W}} \sim 6.9$ occurred in the Nahanni Range of the Northwest Territories (Wetmiller et al. 1988). Deformation rates and b-values determined from regional earthquakes are approximately 4 $\mathrm{mm} / \mathrm{yr}$ and 1, respectively (Hyndman et al. 2005). Earthquake catalogues are complete to magnitude $\mathrm{M} \sim 3$ (Leonard et al. 2008) everywhere except near the Denali Fault, where an increase in seismic station coverage improved the detection limit and allows catalogue completeness down to magnitude $\mathrm{M} \sim 1$ (Meighan et al. 2013). These earthquake parameters are useful in building seismic hazard maps for the southwestern part of the NCC (Cassidy et al. 2005); however uncertainties in hazard estimates are large in other parts of the Cordillera.

Most earthquakes that occur in the NCC have large location uncertainties due to: 1) a very sparse network of seismograph stations (prior to 2013); and 2) a poorly constrained crustal 
velocity model (Cassidy et al. 2005). The current seismic velocity model used by the Geological Survey of Canada (referred to as the GSC model) to locate earthquakes in the Cordillera consists of a uniform, $36 \mathrm{~km}$-thick crustal layer overlying a mantle half-space. Both of these limitations prevent an accurate and precise mapping of focal depth and active faults from earthquake hypocenters. Since 2013, several (>20) seismograph stations were installed as part of separate experiments (e.g., the Yukon-Northwest Seismograph Network) or as part of the Transportable Array of USArray. Coverage is now adequate for catalogue completeness down to magnitude $\mathrm{M}<3$ in most parts of the Cordillera. However, the crustal seismic velocity model used to determine earthquake hypocenters remains poorly constrained. Crustal structure has been imaged along deep seismic reflection and refraction profiles obtained as part of the Lithoprobe SNORCLE transect in southern Yukon (e.g., Cook et al. 2004; Creaser and Spence 2005; Snyder et al. 2009; Calvert 2016). The seismic velocity structure in other parts of the NCC remains unconstrained by seismic data.

On 29 August 2014, a moderate earthquake with magnitude $M_{B} 5.0$ occurred in the Northwest Territories, Canada, approximately $100 \mathrm{~km}$ away from the Cordilleran Deformation Front, which we will refer to as the 2014 Great Bear Lake (GBL14) earthquake. Figure 1 shows the distribution of stations that recorded clear Rayleigh waves from the earthquake at dominant periods of 5 to 29 s. Figure 2 shows the 23 Rayleigh wave seismograms. As a rule of thumb, the peak Rayleigh wave sensitivity in group velocity occurs at a depth (km) similar to the period (s) (e.g., Lowrie 2007). Therefore, at these short periods the Rayleigh waves travel mainly in the crust and can be used to retrieve the crustal seismic velocity structure of the region from group 
velocity dispersion measurements. In this paper we estimate $S$-wave velocity models of the crust across the northern Canadian Cordillera using these Rayleigh wave dispersion data.

In the following sections, we describe the procedure to obtain an $S$-wave velocity model between the station ISLE, located in southeastern Alaska, and the epicentre (Fig. 1). Using the same procedure we retrieve 23 models between each station and the epicenter. Crustal models are then grouped according to similarity in station azimuth, resulting in 13 different crustal seismic velocity models that are examined for consistency. The models are further averaged into a single, final model, which is used to produce synthetic receiver function data that are compared with observations, and to examine the error in earthquake location caused by the use of over-simplified crustal velocity models.

\section{Rayleigh wave group velocity measurements}

Moderate and strong regional earthquakes typically produce large Rayleigh wave signals on vertical component seismograms. These surface waves sample different parts of the crust and upper mantle according to their wavelength. Long wavelengths (long periods) will penetrate deeper in the subsurface and travel at a higher wave speed compared to shorter wavelengths (shorter periods) that travel through a shallower and seismically slower medium. The dispersive nature of surface waves can thus be used to retrieve information on the crustal velocity structure between a source and a receiver.

The first step in the analysis involves removing the instrument response and obtaining displacement records. The power spectra of most Rayleigh wave displacement seismograms for the GBL14 earthquake have dominant energy between 5 and 30 seconds. An example for station 
ISLE is shown in Figure 3. The Rayleigh waves recorded at other stations have similar Fourier spectra and dominant period range. We use a wider band pass filter with corner frequencies at 1 and 50 seconds to avoid leakage effects when measuring dispersion. After we obtain the displacement records, we select the seismograms that contain clear Rayleigh waves in the period range of interest. Following this step, we measure the group velocity dispersion curves using the multiple filter technique (Dziewonski et al. 1969; Herrmann and Ammon 2002). This technique essentially applies various Gaussian filters to a pre-processed displacement seismogram and estimates the group arrival time associated with each filter as the time for which the envelope has maximum amplitude. We then obtain group velocity curves by dividing the epicentral distance by the group arrival time. An example of the measured group velocities for station ISLE is shown in Figure 4. The curve formed by joining the small squares is the dispersion curve, which corresponds to the fundamental mode of the Rayleigh wave.

\section{Inversion for crustal velocity models}

Once a group dispersion curve is measured at a given seismic station, we can use it to determine an average 1-D $S$-wave velocity profile along the source-receiver path. We estimate $S$-wave velocity models using the linearized inversion software of Hermann and Ammon (2002) and Hermann (2013). In this approach we first set up an initial crustal model, and then revise the model based on the fit between the observed dispersion data and the predicted dispersion curve generated using the revised model until convergence is reached. All models are parameterized using 20 layers with uniform velocity of thickness varying between 1 to $3 \mathrm{~km}$ between the surface and $38 \mathrm{~km}$, underlain by a mantle half space. The thicknesses of the layers are held fixed 
while the seismic velocities are allowed to vary. We use the initial crustal velocity model from Ma (2010), modified to include a discontinuity in seismic velocity at a depth of $28 \mathrm{~km}$ simulating a reflective boundary separating middle to lower crust (e.g., Snyder et al. 2009), and set the Moho depth to $34 \mathrm{~km}$ based on average results from previous studies (e.g., Perry et al. 2002; Creaser and Spence 2005; Kao et al. 2013).

The example for station ISLE is shown in Figure 5. The left panel shows the retrieved $S$-wave velocity model and the initial model. We then compare the consistency between the observed dispersion data and the predicted group velocity curve to determine if the recovered velocity model is reasonable. The right panel in Figure 5 shows the observed group velocities (small triangles) and the predicted group velocity curve (solid curve). The two curves are consistent throughout the period range between $5.5 \mathrm{~s}$ and $29 \mathrm{~s}$ (Table 1), indicating an acceptable solution, albeit not unique. At the periods measured, the Rayleigh waves penetrate to a maximum depth of about $35 \mathrm{~km}$, implying that the retrieved velocity model represents the $1 \mathrm{D}$ crustal velocity averaged along the path between the station ISLE and the epicenter. Below $35 \mathrm{~km}$, the retrieved $S$-wave velocity model may be not reliable. Finally, we convert the $S$-wave velocity model to $P$-wave velocity and density using values for a Poisson solid $\left(V_{P} / V_{S}=1.732\right)$ and the Nafe-Drake relation (Ludwig et al. 1970).

We check the reliability of the solution by forming two new sets of Rayleigh wave dispersion data: one formed by adding the error in the group velocity curve to the measured values; and the other set formed by subtracting the error in the measured group velocities. Figure 6a shows the observed group velocity curve and the two new curves. Using these three curves we retrieve three 
crustal models. Figure 6b shows these three models as well as the initial model. This exercise shows that our solution is everywhere slower than the initial model, even when considering the maximum error in the data.

To investigate the sensitivity of the solution to the initial seismic velocity model, we perform a second inversion using the GSC model as our starting point. This model is characterized by a simple one-layer crust over a half-space mantle with uniform properties (Table 2). The best-fit solution using this initial seismic velocity model is shown in Figure 7. The two solutions (Figs. 5 and 7) show very similar structure at shallow depth $(<20 \mathrm{~km})$, indicating that the solutions are robust. At deeper levels, the solutions start to diverge, but the misfit between the observed and synthetic dispersion curves is higher compared to our first solution. We therefore use our first initial seismic velocity model to compute an average velocity model for the NCC.

\section{Crustal seismic velocity models across the Cordillera}

We use seismograms recorded at 23 stations with clear Rayleigh wave signals from the GBL14 earthquake (Figs. 1 and 2), and measure their dispersion curves. For each record, the source parameters, station distance, station azimuth, and the shortest and longest periods are shown in Table 1. Once we obtain the dispersion curve for a given station, we perform the inversion using the same procedure as outlined above and produce 23 crustal velocity models. We then divide the 23 models into 13 groups based on the azimuth between the earthquake and the stations (Fig. 1). Some groups contain only one station, whereas other groups contain up to 5 stations (Table 1). We then average the velocity models within each group, which are shown in Figure 8 and listed in Supplementary Table S1. Groups that contain widely separated stations 
(e.g., groups 1 and 5) may sample very different crust, resulting in a smoothed model.

Despite some interesting variability, all recovered models show slower seismic velocities compared to the initial model. Some models retrieved along paths that sample thick sedimentary sequences and across the Mackenzie Mountains (e.g., panels 4, 5, 7, 9) show a much-reduced upper crustal velocity (down to $\sim 10 \mathrm{~km}$ depth). Seismic velocities in the lower crust are much slower than the initial model. The middle crustal layer is relatively fast compared to both upper and lower crust, indicating possible structural layering in the crust.

Figure 9 shows the distribution of average shear-wave velocities within separate depth intervals corresponding to upper crust ( 0 to $10 \mathrm{~km})$, middle crust (10 to $28 \mathrm{~km}$ ), lower crust (28 to $34 \mathrm{~km})$ and underlying mantle $(>34 \mathrm{~km})$. We plot the shear-wave velocities as the percent difference between the average value determined within each group with respect to the average value for all groups, plotted as coloured lines linking each group to the GBL14 earthquake. These maps reveal that paths traveling from the source to stations in central Alaska (group 12) are consistently faster than the average overall velocities at middle to upper mantle depths, whereas paths traveling along azimuths to the southwest show systematically lower velocities. These results indicate potential 3-D heterogeneity in seismic velocity beneath much of the NCC. However, mapping these variations would require significantly more sources located around the NCC in order to perform a formal tomographic inversion, and is outside the scope of this study.

Finally, we further average velocity models that sample the Cordillera (models 5-13) into a single mean velocity model where each model is weighted equally. The model is consistent with a recent seismic velocity model obtained from refraction data (Calvert 2016) that shows 
increasing $P$-wave velocities from $\sim 5.6 \mathrm{~km} / \mathrm{s}$ in the upper crust to $\sim 6.4 \mathrm{~km} / \mathrm{s}$ at $35 \mathrm{~km}$, near the crust-mantle boundary.

\section{Comparison with receiver functions}

We use the crustal seismic velocity model obtained from the Rayleigh wave data averaged over paths 5 to 13 to generate synthetic receiver functions that we compare with observed data. Receiver functions are sensitive to subsurface velocity contrasts (vertical resolution of $\sim 1-10 \mathrm{~km}$ ) directly beneath a recording station, whereas Rayleigh waves sample the crust along a path, and are more sensitive to vertical gradients in the seismic velocity structure. Therefore, we may expect significant differences between receiver functions calculated from a Rayleigh wave-based average velocity model and observed receiver function data. Nevertheless, the comparison can give insights into how well the average seismic velocity model captures body-wave scattering properties, especially any intra-crustal seismic discontinuity that may be required by both data sets.

We select three stations (MMPY, FARO and TGTN) that are located in the central part of the NCC. We extract $P$-wave seismograms for all teleseismic events in the epicentral distance range of $30-90^{\circ}$ that pass a signal-to-noise threshold of 5 on the vertical component. The methodology for receiver function calculation is based on Wiener deconvolution and the details can be found elsewhere (e.g., Audet 2010). We stack radial component receiver functions and plot them as an average trace (Fig. 10). Synthetic receiver function data are calculated using a reflectivity technique (e.g., Audet 2016) using earthquake parameters (i.e., horizontal slowness) for the event distribution obtained at station MMPY, which is representative of the event distribution of the 
other two stations. Synthetic receiver functions are similarly averaged and shown as a single trace (Fig. 10).

The synthetic receiver function trace shows simple phase arrivals associated with a main $P$-to- $S$ conversion from the sharp downward velocity increase at the Moho at $\sim 4 \mathrm{~s}$, and free-surface reverberations ( $P p s$ and $P s s)$ at $\sim 15$ and $\sim 18$ s. The observed receiver functions at stations FARO, MMPY and TGTN generally show similar features. In particular, all traces show the various phase arrivals but their timing can vary by $\sim 10-20 \%$. For instance, the receiver function for station FARO shows earlier phase arrivals, indicating either faster background velocities or thinner crust.

Observed receiver functions also display additional, lower amplitude arrivals, which reflect local departures from the average and smooth crustal seismic velocity model. For example, we observe a high-amplitude negative pulse at $\sim 5-6 \mathrm{~s}$ at station MMPY that may indicate a high-velocity layer below the Moho, which is not captured by the surface-wave based model. Receiver function data at station TGTN display a very high-amplitude positive pulse near zero lag time, which may suggest the presence of a very thin, very low velocity layer (e.g., sedimentary basin) near the surface. In addition, the lower crustal boundary at depth of $28 \mathrm{~km}$ that is consistent with surface-wave data is not well resolved as a positive Ps conversion (which would appear at times $<4 \mathrm{~s}$ ), but may be resolved by the later reverberations (e.g., double negative pulses between 17 and $21 \mathrm{~s}$ in the synthetic data). This signature may be observed at station FARO, but it not pervasive. We propose that the highly reflective lower crustal boundary, as observed by active source data, may not be detected by receiver functions. Alternatively, if the 
lower crust forms a lower crustal shear zone (as suggested by some authors, e.g., Mazzotti and Hyndman 2002), the associated fabrics may give rise to seismic anisotropy that can be detected by looking at back-azimuth variations in the receiver function signals. However, this is outside the scope of this study.

\section{Effects on earthquake locations}

The accurate determination of earthquake hypocenters for local or regional earthquakes requires precise phase picks (such as $P g$ and $S g$ phases) and a reliable crustal model in the earthquake source region. The GSC model used in the determination of earthquake locations is shown in Figure 11. Since there are important differences between our solution and the GSC model, we evaluate their effects on estimates of earthquake hypocenters. For this exercise we further smooth our average velocity model to decrease the number of layers and improve the efficiency of the inversion for hypocentral location (Fig. 11). In addition we test two end-member mantle half-space models to account for the uncertainty in recovered mantle velocities using our surface-wave data set, with $P$-wave velocities of either $8.2 \mathrm{~km} / \mathrm{s}$ or $7.6 \mathrm{~km} / \mathrm{s}$.

We use the 2014-09-19 $\mathrm{M}_{\mathrm{L}}$ 4.1, and the 2015-10-21 $\mathrm{M}_{\mathrm{W}} 4.7$ earthquakes, which occurred in the NCC and are listed in the catalogue produced by the National Earthquake Information Center (NEIC), to compare source locations using various seismic velocity models. We retrieve waveform records for these two earthquakes and measure the arrival times of $P g$ and $S g$ phases at a number of selected stations that have clear phase onsets. Tables $\mathbf{2}$ and $\mathbf{3}$ list the measured arrival times. We relocate the two earthquakes using the arrival times and the crustal models in Figure 11 as input to the computer program HYPOINVERSE by Klein (2014 version). Tables 4 
and 5 list the source parameters we obtained, as well as those determined by the NEIC.

For the $\mathrm{M}_{\mathrm{L}} 4.1$ earthquake, the solution with lowest RMS and location uncertainties is obtained using the average crustal seismic velocity model from the Rayleigh wave data with mantle half-space $P$-wave velocity of $7.6 \mathrm{~km} / \mathrm{s}$. This solution also shows a realistic focal depth of $5.63 \mathrm{~km}$, as opposed to a surface (fixed at $1 \mathrm{~km}$ ) location obtained from the NEIC. The distance between the lowest RMS solution and that of the NEIC is $11.6 \mathrm{~km}$, and $10.8 \mathrm{~km}$ when compared with the solution obtained using the GSC model. For the $\mathrm{M}_{\mathrm{W}} 4.7$ earthquake, the solution with lowest RMS and location errors is obtained using the average crustal seismic velocity model with mantle half-space $P$-wave velocity of $8.2 \mathrm{~km} / \mathrm{s}$, but the RMS and location error are similar to those obtained with the GSC model. In this case the distance between the lowest RMS solution and the NEIC solution is $6.3 \mathrm{~km}$.

The two different half-space mantle models that produce the best (i.e., lowest RMS) hypocentral solutions suggest either that upper mantle velocities vary laterally across the northern Canadian Cordillera, or that the upper mantle is highly anisotropic (Audet et al. 2016). In addition, using an average 1-D seismic velocity model for the entire Cordillera may introduce large errors in hypocentral locations. Nevertheless, we found that the differences between the source parameters obtained using the GSC model, our new model, and those provided by the NEIC are small. However, these errors might be significant when trying to identify the faults responsible for the earthquakes in the field, and to establish accurate earthquake focal depths.

\section{Discussion and conclusion}

The 29 August $2014 \mathrm{M}_{\mathrm{B}} 5.0$ earthquake generated excellent crustal Rayleigh wave records. 
We retrieve crustal seismic velocity models for paths that propagate across the northern Canadian Cordillera using Rayleigh wave dispersion data. The seismic velocities in the retrieved models are everywhere slower than those in the initial model, consistent with the eastern Cordilleran crust containing Late Cretaceous miogeoclinal basin structures (e.g., Monger and Price 2002) that are typically characterized by low seismic velocities. Significant variations in 1-D velocity structure do exist across the Cordillera, which indicate heterogeneous crustal and upper mantle structure beneath the Cordillera. These variations may reflect complex geological events (e.g., terrane accretion and transcurrent motion along the Tintina Fault) that have shaped the northern Cordillera through its tectonic history. Resolving these variations is important, among other things, in understanding the metallogeny and mineral potential in the Cordillera (e.g., Lund 2007). Unfortunately, our analysis does not allow us to robustly infer the 3-D seismic velocity structure due to incomplete illumination by a single earthquake source. This goal can be accomplished using multiple earthquake sources distributed around the NCC, and performing a formal tomographic inversion of surface wave dispersion data. Instead, in this paper we are interested in obtaining a representative crustal seismic velocity model that can be used for improving earthquake locations.

The average seismic velocity model that we obtain here is not unique, and other models can fit the data equally well. We have shown, however, that the final solution is relatively insensitive to the initial model used in the inversion, and that it compares well with independent receiver function data. In particular, receiver function data indicate that the Moho is relatively flat and consistent with a depth of $34 \mathrm{~km}$. Because surface waves tend to smooth out lateral variations in 
structure, some discrepancies are expected. The seismic discontinuity at lower crustal depth that matches the surface-wave data produces characteristic reverberative signals in synthetic receiver functions that are not consistently observed in the data. This may imply that the lower crustal boundary, if it exists, may be poorly constrained by receiver function data. Alternatively, if the boundary represents a lower crustal shear zone (e.g., Mazzotti and Hyndman 2002), the signature of lower crustal fabrics may be expressed as seismic anisotropy signals that we ignored in this study. These various models can be further tested in a future study by jointly inverting surface-wave dispersion and receiver function data.

We further tested the effect of our final velocity model in obtaining accurate source locations of two regional earthquakes that occurred in the NCC. After picking the arrival times of $P g$ and $\mathrm{Sg}$ phases from regional stations, we locate the earthquakes using two seismic velocity models: one based on a smoothed version of the model determined using the surface-wave dispersion data and one routinely used by the Geological Survey of Canada. By simply changing the velocity model used in earthquake location, we find differences in epicentral locations up to $10 \mathrm{~km}$. We further compare these locations with the NEIC catalogue locations, and find similar differences of up to $10 \mathrm{~km}$. We therefore conclude that our seismic velocity model may improve earthquake locations and allow a more precise mapping of active crustal faults in the northern Cordillera.

\section{Acknowledgements}

We thank two anonymous reviewers and the Associate Editor for comments that significantly improved this paper. We gratefully acknowledge the financial support of the Natural Sciences and Engineering Research Council of Canada and the Ontario Ministry of Research and 
Innovation. Some figures were prepared using the Generic Mapping Tools software (Wessel and Smith, 1998). The facilities of IRIS Data Services, and specifically the IRIS Data Management Center, were used for access to waveforms, related metadata, and/or derived products used in this study. IRIS Data Services are funded through the Seismological Facilities for the Advancement of Geoscience and EarthScope (SAGE) Proposal of the National Science Foundation under Cooperative Agreement EAR-1261681. We wish to thank the various federal, territorial and municipal agencies in the Yukon and Northwest Territories (YT Highway and Public Works, YT Energy Mines and Resources, Town of Faro, BC Wildfire Department, NT Environment and Natural Resources, and Nav Canada) for allowing us access to their land in the installation of the Yukon-Northwest Seismograph Network.

\section{References}

Audet, P. (2010). Temporal variations in crustal velocity structure near Parkfield, California, using receiver functions, Bulletin of the Seismological Society of America, 100, 1356-1362.

Audet, P. (2016). Teleseismic receiver functions using OBS data: Promises and limitations from numerical modelling and examples from the Cascadia Initiative, Geophysical Journal International, 205, 1740-1755

Audet, P., Sole, C., and Schaeffer, A.J. (2016). Control of lithospheric inheritance on neotectonic activity in northwestern Canada? Geology, doi:10.1130/G38118.1

Calvert, A. J. (2016). Seismic interpretation of crustal-scale extension in the Intermontane Belt of the northern Canadian Cordillera, Geology, 44, 447-450.

Cassidy, J.F., G.C. Rogers, and J. Ristau (2005). Seismicity in the vicinity of the SNORCLE corridors of the northern Canadian Cordillera, Can. J. Earth Sci., 42, 1137-1148.

Cook, F. A., R. M. Clowes, D. B. Snyder, A. J. van der Velden, K. W. Hall, P. Erdmer, and C. A. Evenchick (2004). Precambrian crust beneath the Mesozoic northern Canadian Cordillera 
discovered by Lithoprobe seismic reflection profiling, Tectonics, 23, TC2010, doi:10.1029/2002TC001412.

Creaser B. and G. Spence (2005). Crustal structure across the northern Cordillera, Yukon Territory, from seismic wide-angle studies: Omineca Belt to Intermontane Belt. Can. J. Earth Sci. 42, 1187-1203.

Dziewonski, A., S. Bloch, and M. Landisman (1969). A Technique for the Analysis of Transient Seismic Signals, Bull. Seism. Soc. Am., 59, No. 1, 427-444.

Herrmann, R.B. (2013). Computer Programs in Seismology: An evolving tool for instruction and research. Seis. Res. Lett. 84 1081-1088; doi:10.1785/0220110096.

Herrmann, R. and C. Ammon (2002). Computer Programs in Seismology, version 3.30, Saint Louis University, Missouri, USA.

Hyndman, R.D., P. Flück, S. Mazzotti, T.J. Lewis, J. Ristau, and L. Leonard (2005). Current tectonics of the northern Canadian Cordillera, Can. J. Earth Sci., 42, 1117-1136.

Kao, H., Y. Behr, C. A. Currie, R. Hyndman, J. Townend, F.-C. Lin, M. H. Ritzwoller, S.-J. Shan, and J. He (2013). Ambient seismic noise tomography of Canada and adjacent regions: Part 1. Crustal structures, J. Geophys. Res., 118, 5865-5887.

Klein, F.W. (2014). User's guide to HYPOINVERSE-2000, a Fortran program to solve for earthquake locations and magnitudes, USGS Open File Report, 02-171.

Leonard, L., S. Mazzotti, and R.D. Hyndman (2008). Deformation rates estimated from earthquakes in the northern Cordillera of Canada and eastern Alaska, J. Geophys. Res., 113, B08406, doi:10.1029/2007JB005456.

Lowrie, William (2007). Fundamentals of Geophysics, Cambridge University Press, 381 pp.

Ludwig, W.J., J.E. Nafe, and C.L. Drake (1970). Seismic refraction, in The Sea, A. E. Maxwell, (Editor) Vol. 4, Wiley-Interscience, New York, 53-84.

Lund, K. (2007). Geometry of the Neoproterozoic and Paleozoic rift margin of western Laurentia: Implications for mineral deposit settings

Ma, S. (2010). Focal Depth Determination for Moderate and Small Earthquakes by Modeling Regional Depth Phases $s P g, s P m P$, and $s P n$, Bull. Seism. Soc. Am., 100, 1073-1088. 
Mazzotti, S., and R. D. Hyndman (2002). Yakutat collision and strain transfer across the northern Canadian Cordillera. Geology, 30, 495-498.

Meighan, L.N., J.F. Cassidy, S. Mazzotti, and G.L. Pavlis (2013). Microseismicity and tectonics of southwest Yukon Territory, Canada, using a local dense seismic array. Bull. Seism. Soc. Am., 103, 3341-3346.

Monger, J., and R. Price (2002). The Canadian Cordillera: Geology and tectonic evolution, CSEG Recorder, 27, 17-36.

Perry, H. C. K., D. W. S. Eaton, and A. M. Forte (2002). LITH5.0: A revised crustal model for Canada based on Lithoprobe results, Geophys. J. Int., 150, 285-294.

Snyder, D. B., M. Pilkington, R. M. Clowes, and F. A. Cook (2009). The underestimated Proterozoic component of the Canadian Cordillera accretionary margin, in Cawood, P. A. and Kroner, A. (eds) Earth Accretionary Systems in Space and Time, The Geological Society, London, Special Publication, 318, 257-271.

Wessel, P. and W. H. F. Smith (1998). New, improved version of the Generic Mapping Tools released, Eos Trans. AGU, 79(47), 579.

Wetmiller, R.J., R.B. Horner, H.S. Hasegawa, R.G. North, M. Lamontagne, D.H. Weichert, and S.G. Evans (1988). An analysis of the 1985 Nahanni earthquakes, Bull. Seism. Soc. Am., 78, 590-616. 
Table 1. Parameters used to measure the Rayleigh wave dispersion curves. Az is the azimuth between the GBL14 earthquake and the station; T1 and T2 are the shortest and the longest periods considered in the dispersion analysis. Network codes are: TA - Transportable Array; CN - Canadian National Seismograph Network; RV - Regional Alberta Seismic Observatory for Earthquake Studies Network; US - United Stated National Network; NY - Yukon-Northwest Seismograph Network; AK - Alaska Regional Network; YE - Testing TA and Flexible Array Network.

\begin{tabular}{c|cccccc}
\hline Group \# & Network & Station Name & Az $\left(^{\circ}\right)$ & Distance $(\mathrm{km})$ & T1 (s) & T2 (s) \\
\hline \multirow{2}{*}{ G1 } & TA & C36M & 352 & 419 & 4.6 & 29.0 \\
& TA & A36M & 353 & 717 & 5.0 & 28.0 \\
\hline G2 & CN & YKW3 & 127 & 520 & 3.2 & 29.0 \\
\hline G3 & RV & STPRA & 158 & 1170 & 4.8 & 29.0 \\
\hline G4 & CN & NBC1 & 186 & 668 & 5.5 & 26.0 \\
\hline \multirow{2}{*}{ G5 } & US & WRAK & 211 & 1149 & 5.5 & 29.0 \\
& NY & TGTN & 214 & 535 & 5.0 & 29.0 \\
\hline G6 & AK & JIS & 222 & 1022 & 5.0 & 29.0 \\
\hline \multirow{2}{*}{ G7 } & NY & MMPY & 235 & 536 & 4.0 & 29.0 \\
& NY & FARO & 239 & 646 & 4.2 & 29.0 \\
\hline & AK & RKAV & 247 & 1112 & 6.0 & 29.0 \\
& AK & BARK & 249 & 1154 & 4.2 & 29.0 \\
G8 & AK & ISLE & 250 & 1134 & 5.5 & 29.0 \\
& AK & KIAG & 251 & 1113 & 5.5 & 29.0 \\
& AK & BAL & 252 & 1105 & 6.5 & 29.0 \\
\hline G9 & NY & MAYO & 256 & 672 & 4.0 & 29.0 \\
\hline \multirow{2}{*}{ G10 } & AK & KLU & 259 & 1236 & 7.0 & 29.0 \\
& TA & O22K & 260 & 1470 & 6.5 & 29.0 \\
\hline G11 & TA & L26K & 263 & 1037 & 5.5 & 29.0 \\
\hline \multirow{3}{*}{ G12 } & TA & TCOL & 277 & 1173 & 6.0 & 27.0 \\
& AK & MDM & 278 & 1188 & 7.0 & 26.0 \\
& YE & PIC4 & 278 & 1145 & 6.5 & 28.0 \\
\hline \multirow{2}{*}{ Average } & TA & EPYK & 284 & 643 & 4.2 & 29.0 \\
\hline & & & & 938 & 5.3 & 28.6 \\
\hline
\end{tabular}


Table 2. $P g$ and $S g$ arrival times measured for the September 19, 2014, $\mathrm{M}_{\mathrm{L}} 4.1$ earthquake. $P g$ pick times are absolute UTC times; $S g$ pick times represent seconds following the $P g$ pick times.

\begin{tabular}{|l|c|c|}
\hline \multicolumn{2}{|l|}{ 2014-09-19 } & $\mathrm{M}_{\mathrm{L}} 4.1$ \\
\hline Station & $P g$ & $S g$ \\
\hline WHY & $07: 39: 03.40$ & 51.24 \\
\hline FARO & $07: 38: 36.87$ & 65.14 \\
\hline MAYO & $07: 38: 13.16$ & 26.75 \\
\hline MMPY & $07: 38: 38.35$ & 67.59 \\
\hline EPYK & $07: 38: 32.42$ & 57.88 \\
\hline K27K & $07: 38: 52.65$ & 90.38 \\
\hline EGAK & $07: 38: 41.01$ & 78.11 \\
\hline
\end{tabular}

Table 3. $P g$ and $S g$ arrival times measured for the October 21, 2015, Mw 4.7 earthquake. $P g$ pick times are absolute UTC times; $S g$ pick times represent seconds following the $P g$ pick times.

\begin{tabular}{|l|c|c|}
\hline 2015-10-21 & \multicolumn{1}{l|}{$\mathrm{Mw} 4.7$} \\
\hline Station & $P g$ & $S g$ \\
\hline FARO & $20: 34: 06.68$ & 31.49 \\
\hline MAYO & $20: 34: 05.74$ & 33.92 \\
\hline MMPY & $20: 33: 55.25$ & 73.84 \\
\hline TGTN & $20: 34: 13.89$ & 49.22 \\
\hline WGLY & $20: 34: 20.50$ & 62.60 \\
\hline M30M & $20: 34: 16.90$ & 54.40 \\
\hline I29M & $20: 34: 20.80$ & 59.60 \\
\hline N31M & $20: 34: 20.10$ & 63.15 \\
\hline P33M & $20: 34: 29.60$ & 78.20 \\
\hline INK & $20: 34: 28.70$ & 89.10 \\
\hline EGAK & $20: 34: 34.80$ & 84.90 \\
\hline K27K & $20: 34: 40.80$ & - \\
\hline BC04 & $20: 34: 41.60$ & 96.80 \\
\hline L27K & $20: 34: 39.60$ & 96.10 \\
\hline
\end{tabular}


Table 4. The relocated source parameters for the 2014-09-19, $\mathrm{M}_{\mathrm{L}} 4.1$ earthquake. ERH and ERZ are errors (in $\mathrm{km}$ ) in the horizontal and vertical positions.

\begin{tabular}{|c|c|c|c|c|c|c|c|c|}
\hline No. y & origin & Lat. & Long. & Depth & RMS & ERH & ERZ & comments \\
\hline 1 & 2014-09-19 07:37:57.97 & 64.4563 & -134.8267 & 0.03 & 1.59 & 5.99 & 10.99 & GSC hs 8.20 \\
\hline 2 & 2014-09-19 07:37:57.54 & 64.4330 & -134.8733 & 0.03 & 1.92 & 6.30 & 15.77 & Yukon hs 8.20 \\
\hline 3 & 2014-09-19 07:37:55.97 & 64.4315 & -135.0432 & 5.63 & 0.48 & 1.62 & 5.17 & Yukon hs 7.60 \\
\hline & 2014-09-19 07:37:57.52 & 64.4694 & -134.8189 & 1.0 & ИL 4.1 & \multicolumn{2}{|c|}{ (NEIC) } & \\
\hline
\end{tabular}

hs $=$ half space.

Table 5. The relocated source parameters for the 2015-10-21, Mw 4.7 earthquake. ERH and ERZ are errors (in $\mathrm{km}$ ) in the horizontal and vertical positions.

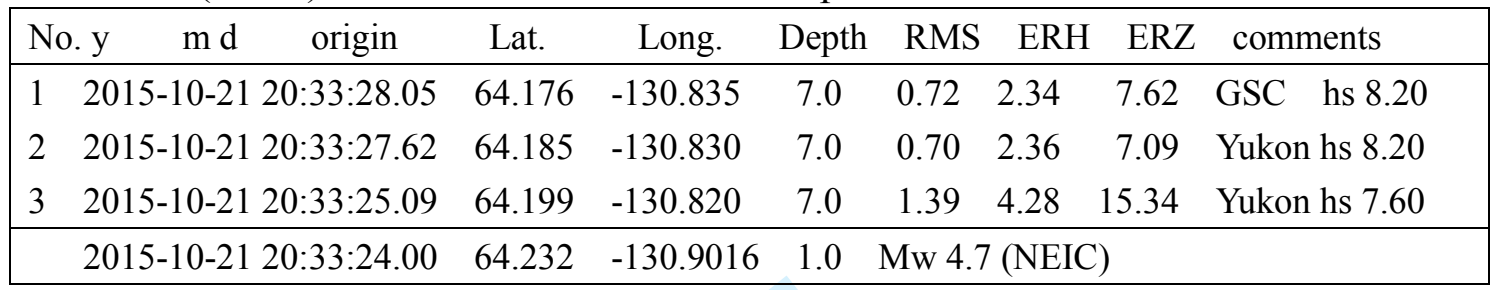

hs $=$ half space. 
Figure 1. Distribution of the 23 seismic stations (inverted red triangles) where Rayleigh waves from the 29 August 2014 Great Bear Lake earthquake (orange star) were clearly observed. These stations were divided into 13 groups according to azimuth sampling, as shown by the numbered dashed lines linking each station group to the earthquake epicenter. The grouping starts at stations $\mathrm{C} 36 \mathrm{M}$ and A36M, moving clockwise to station EPYK. The closest station to the epicenter is $\mathrm{C} 36 \mathrm{M}(419 \mathrm{~km})$, and the farthest is $\mathrm{O} 22 \mathrm{~K}(1470 \mathrm{~km})$. The light blue stars show the location of the $\mathrm{M}_{\mathrm{L}} 4.1$ and $\mathrm{M}_{\mathrm{W}} 4.7$ earthquakes from the NEIC catalogue. Grey circles in the background are earthquake locations from the National Earthquake DataBase (NEDB) between 2000 and 2015. Earthquakes in Alaska are not consistently reported, and the map does not represent the true seismicity in Alaska. Abbreviations are: AK: Alaska; YK: Yukon; BC: British Columbia; NT: Northwest Territories; AB: Alberta; NU: Nunavut; MM: Mackenzie Mountains; NR: Nahanni Range; DF: Deformation Front.

Figure 2. Vertical displacement seismograms of the Rayleigh wave recorded at 23 seismic stations. These waveforms are arranged by azimuthal groups that are identified by the numbers on the right (see Fig. 1). The longest recorded Rayleigh wave train is at station NBC1, whose path mainly samples the sedimentary basin. The records were filtered with a pass band frequency of $0.02-1 \mathrm{~Hz}$.

Figure 3. a) Unfiltered Rayleigh wave displacement record at station ISLE. b) The corresponding power spectrum. The dominant frequencies are from about 0.03 to $0.16 \mathrm{~Hz}$, corresponding to periods of 6 to $30 \mathrm{~s}$. These waves travel mainly through the crust.

Figure 4. Example of group dispersion measurements obtained using the time-frequency analysis technique. The curve formed by tracing the small squares shows the measured group velocities for the fundamental mode at station ISLE (station distance $\sim 1134 \mathrm{~km}$ ). In this case the measured period range is 5.5 to $29 \mathrm{~s}$. Symbols other than squares are not used in the analysis.

Figure 5. (a) Comparison between the retrieved crustal shear-wave velocity model (solid red line) and the initial model (dashed blue line) from the inversion of the phase dispersion curve at station ISLE. (b) Comparison between the observed (small triangles) and the predicted group dispersion curve (solid red curve) generated using the best-fit "new" model in panel (a). The period range used in the inversion is 5.5 to $29 \mathrm{~s}$.

Figure 6. a) The thick curve is the observed dispersion at station ISLE in the period range of 5.5 to $29 \mathrm{~s}$, and the two thin lines are the dispersion curves formed by adding or subtracting the errors to or from the observed dispersion. b) Comparison between crustal velocity models retrieved from the observed dispersion data at station ISLE and the datasets formed by adding or subtracting the measurement errors to the observed data at station ISLE. The thick lines show the $V S$ and $V p$ models retrieved from the observed dispersion data, and the thin lines show the $V_{S}$ and 
$V p$ models retrieved from the two formed dispersion datasets. The thin grey dashed lines labelled "Initial" show the initial model.

Figure 7. (a) Comparison between the retrieved crustal shear-wave velocity model (solid red line) and the initial model (dashed blue line, GSC model used for locating events) in the inversion at station ISLE. (b) Comparison between the observed (small triangles) and the predicted group dispersion curve (solid red curve) generated using the best-fit "new" model at the panel (a).

Figure 8. The retrieved crustal velocity models at 13 azimuthal directions. The thin lines show the initial model, which is identical for all groups. For each panel, the station names appear in the upper right corner, and the group index and azimuth are in the bottom left corner (e.g. 1-353 indicates group 1 at azimuth $353^{\circ}$, the average of the azimuths of stations A36M and C36M). We calculated two average seismic velocity profiles based on geographic distribution. Paths 1 to 4 sample the Canadian Shield basement, whereas paths 5 to 13 sample the Cordillera.

Figure 9. Maps of shear-wave velocity difference calculated with respect to the average velocity at various depth intervals: a) upper crust from 0 to $10 \mathrm{~km}$; b) middle crust from 10 to $28 \mathrm{~km}$; c) lower crust from 28 to $34 \mathrm{~km}$; and d) upper mantle below $34 \mathrm{~km}$. The mean velocity within each depth interval is indicated above each plot.

Figure 10. Observed and synthetic receiver function averages for stations located in the central part of the northern Canadian Cordillera. The synthetic trace is obtained by modeling wave propagation from the average of the velocity models for the groups 5 to 8 (Figs. 1 and 6). The $P$-to- $S$ Moho conversion at $\sim 4 \mathrm{~s}$ observed at all stations is well reproduced by the model. The free-surface reverberations ( $P p P s$ and $P p S s$ ) show up to $1 \mathrm{~s}$ difference with the modeled trace, perhaps reflecting non-uniform $V p / V s$ values across the Cordillera or complications due to local structure.

Figure 11. Simplified new crustal seismic velocity model in Yukon region and the GSC model used for locating events. 


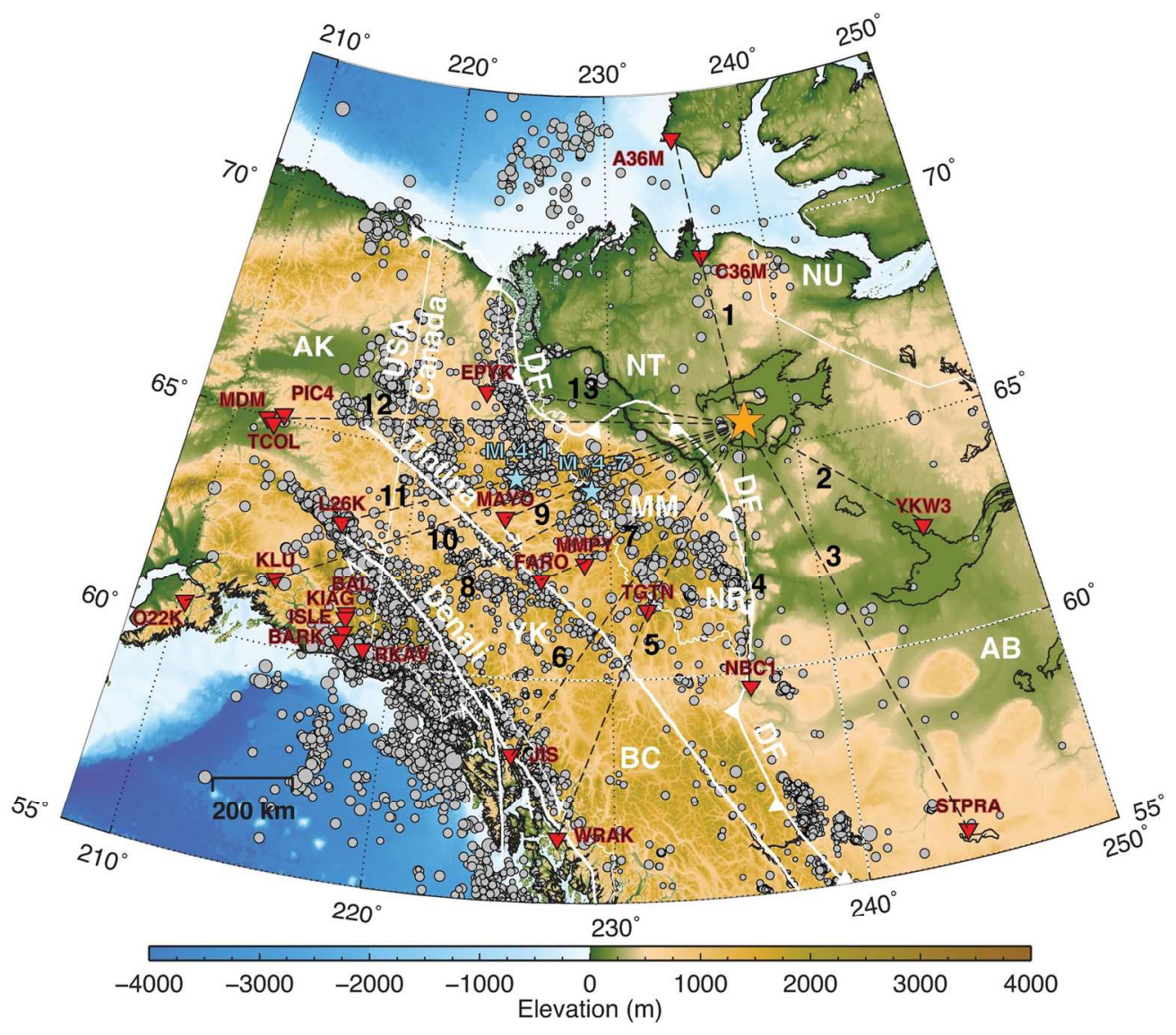

Figure 1

$146 \times 127 \mathrm{~mm}(300 \times 300 \mathrm{DPI})$ 


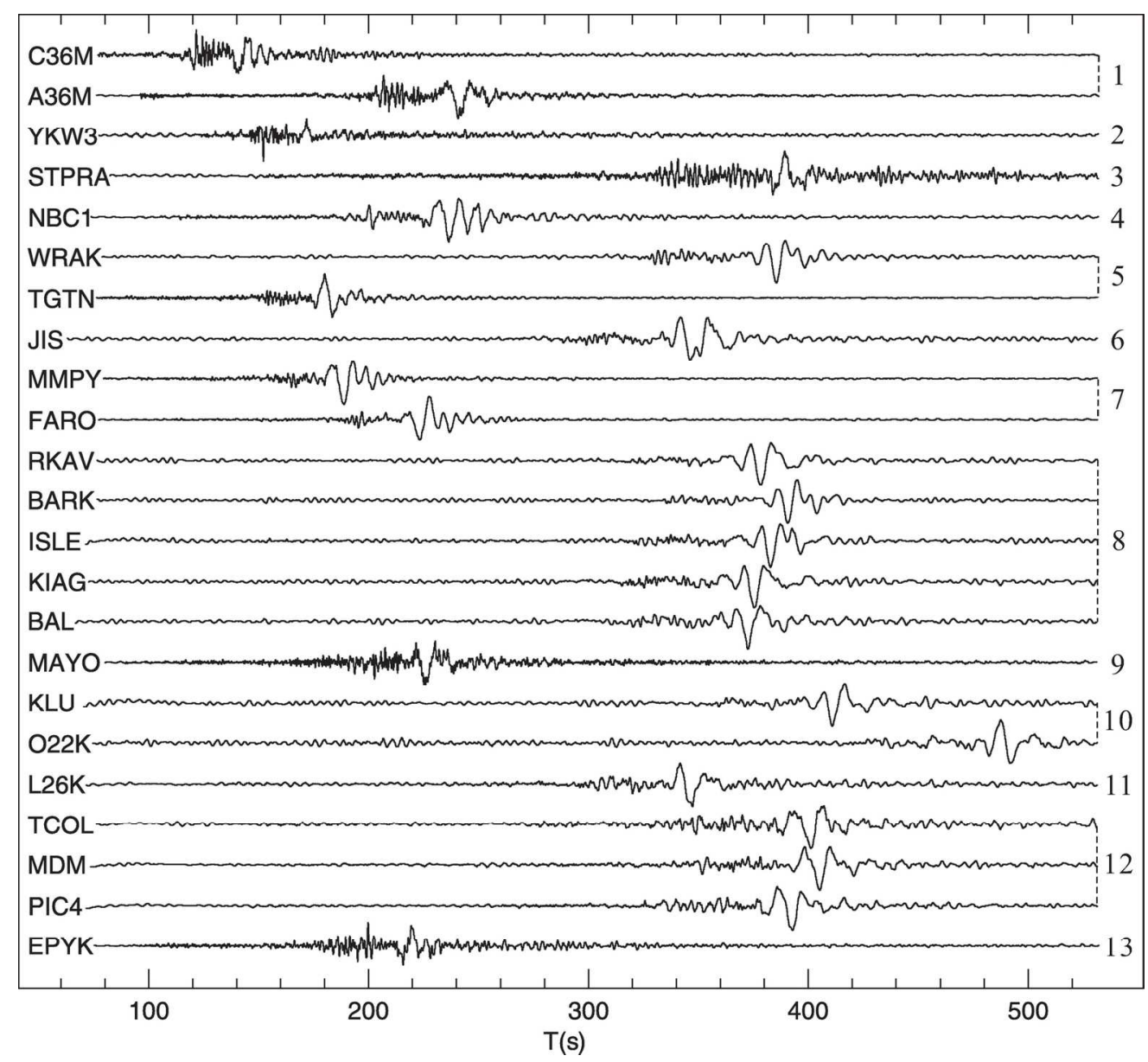

Figure 2

$150 \times 138 \mathrm{~mm}(300 \times 300 \mathrm{DPI})$ 

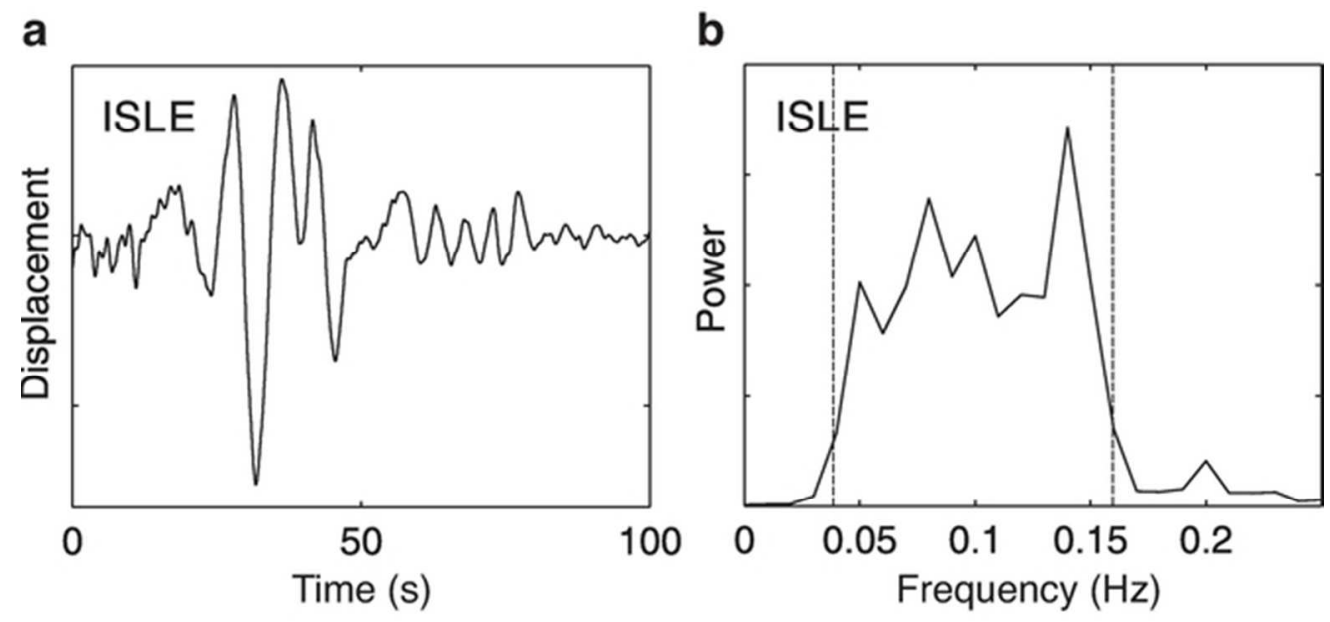

Figure 3

$56 \times 26 \mathrm{~mm}(300 \times 300$ DPI $)$ 


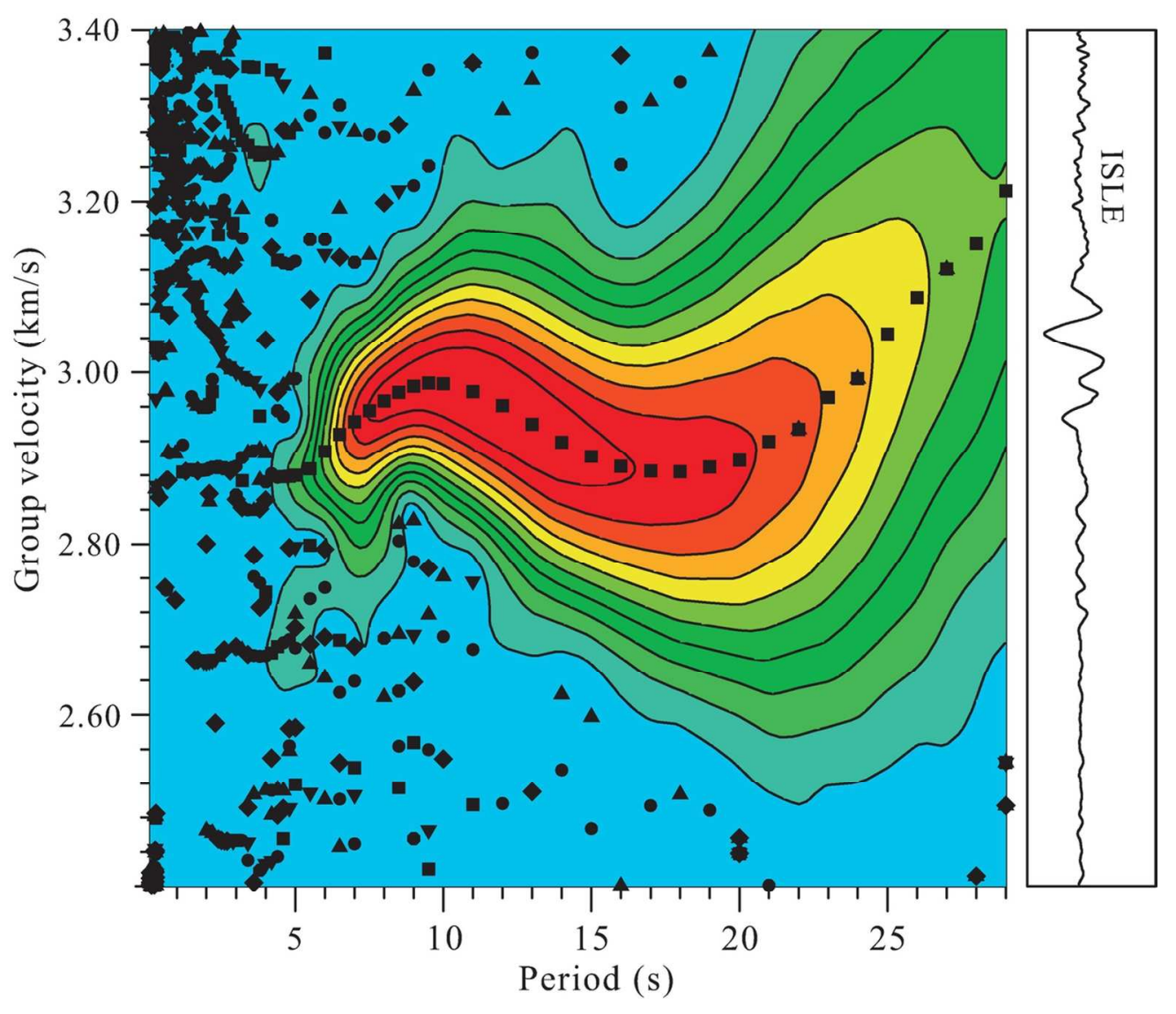

Figure 4

$117 \times 100 \mathrm{~mm}(300 \times 300 \mathrm{DPI})$ 

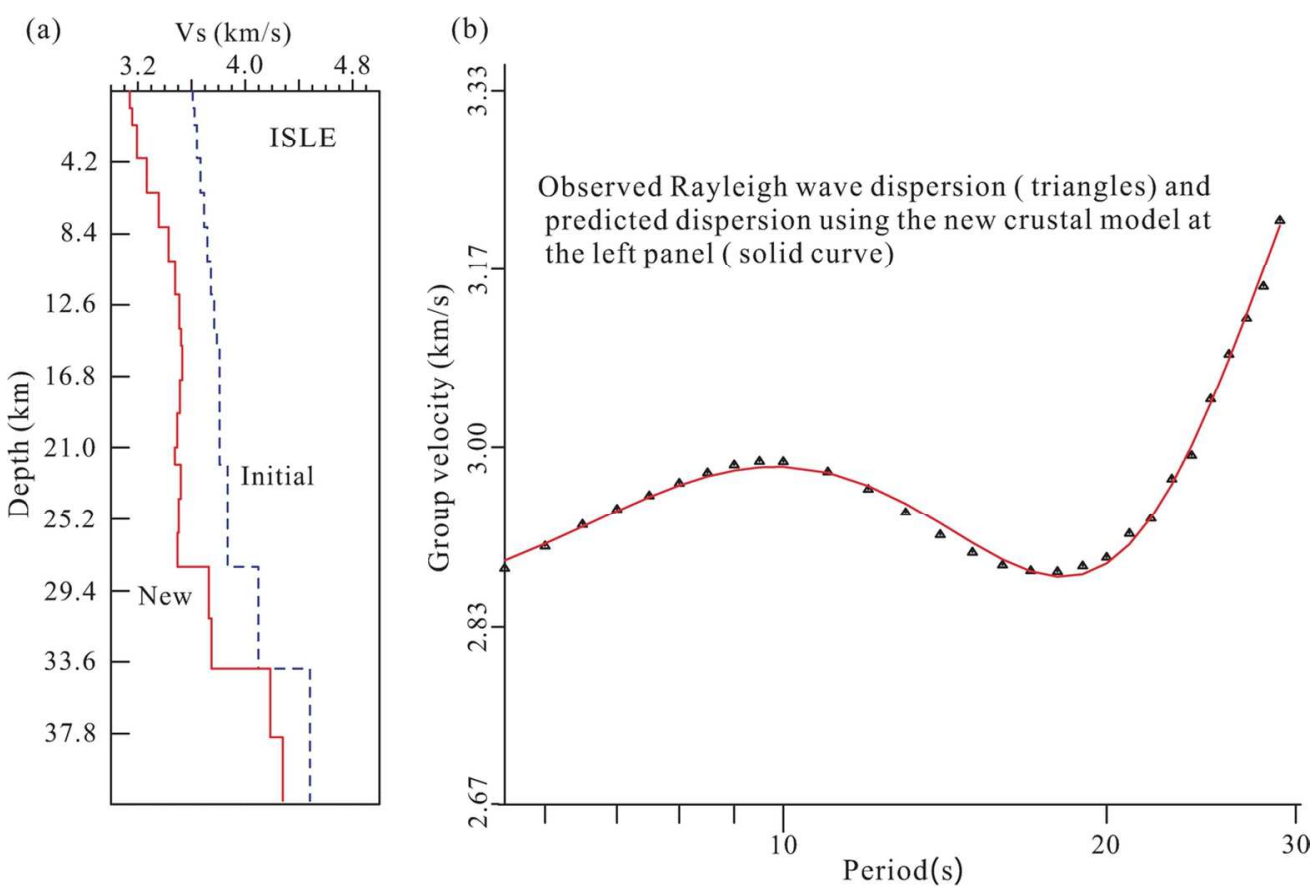

Figure 5

$123 \times 82 \mathrm{~mm}(300 \times 300$ DPI $)$ 
a

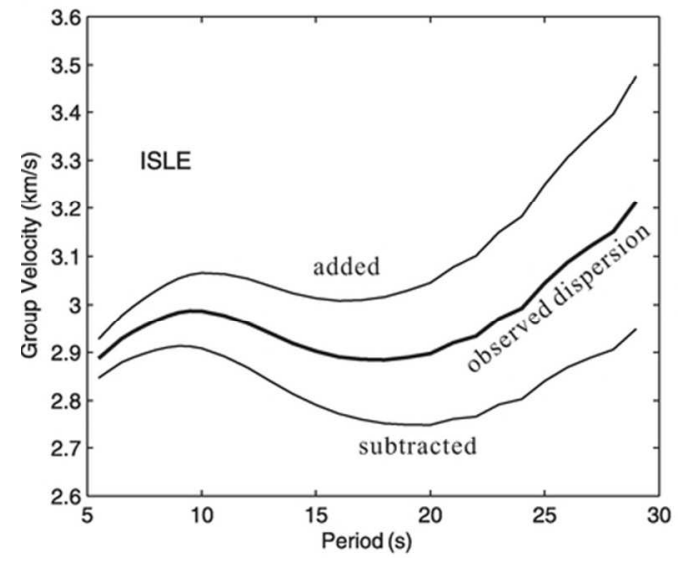

b

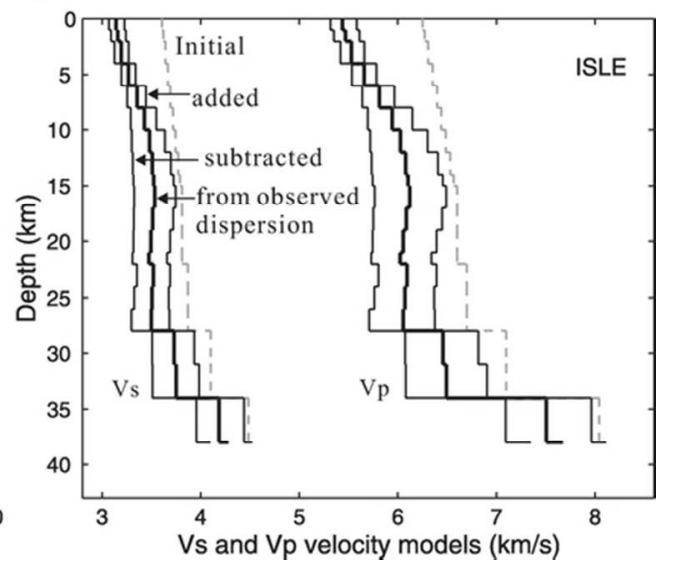

Figure 6

$72 \times 32 \mathrm{~mm}(300 \times 300$ DPI $)$ 


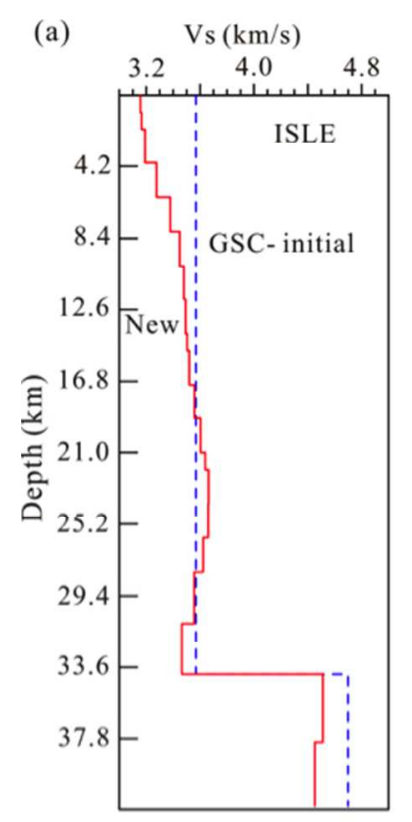

(b)

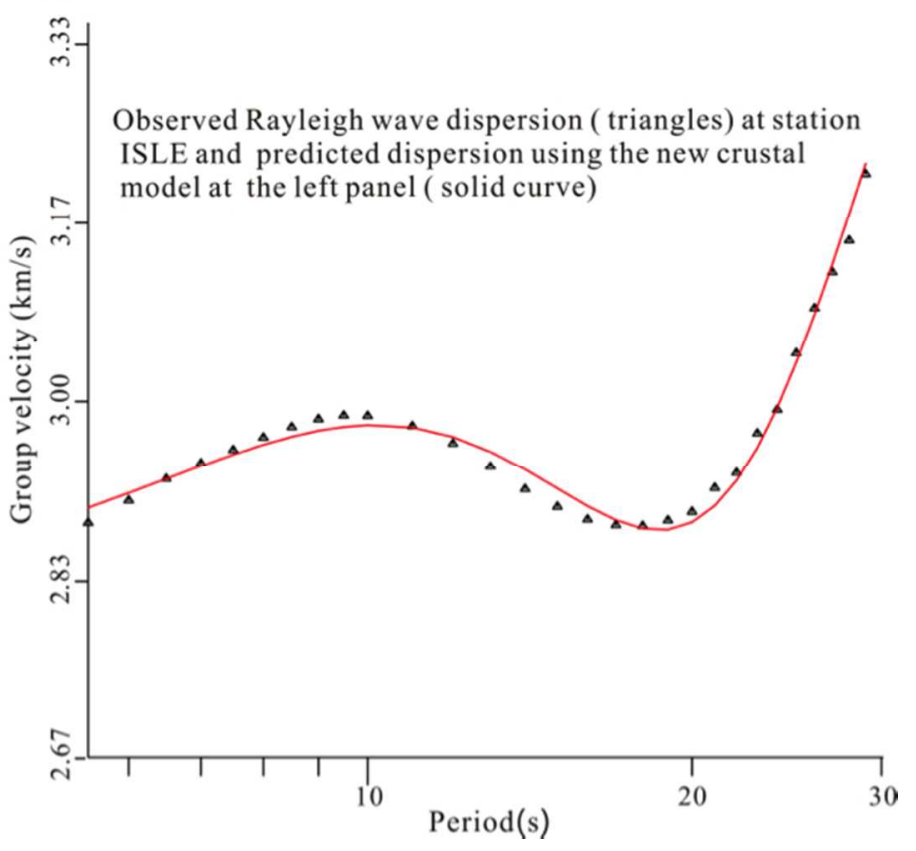

Figure 7 

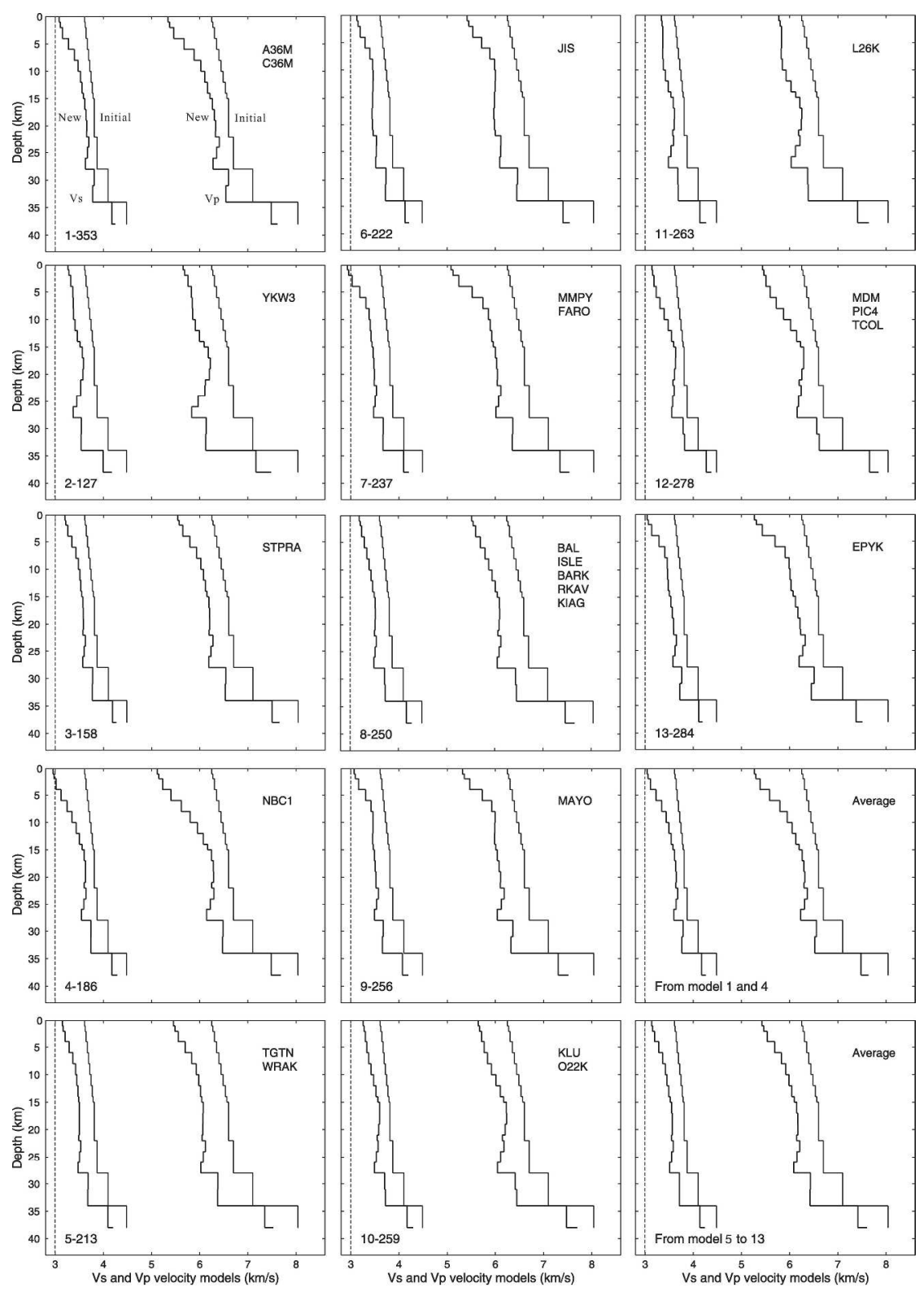

Figure 8

$256 \times 360 \mathrm{~mm}(300 \times 300$ DPI) 

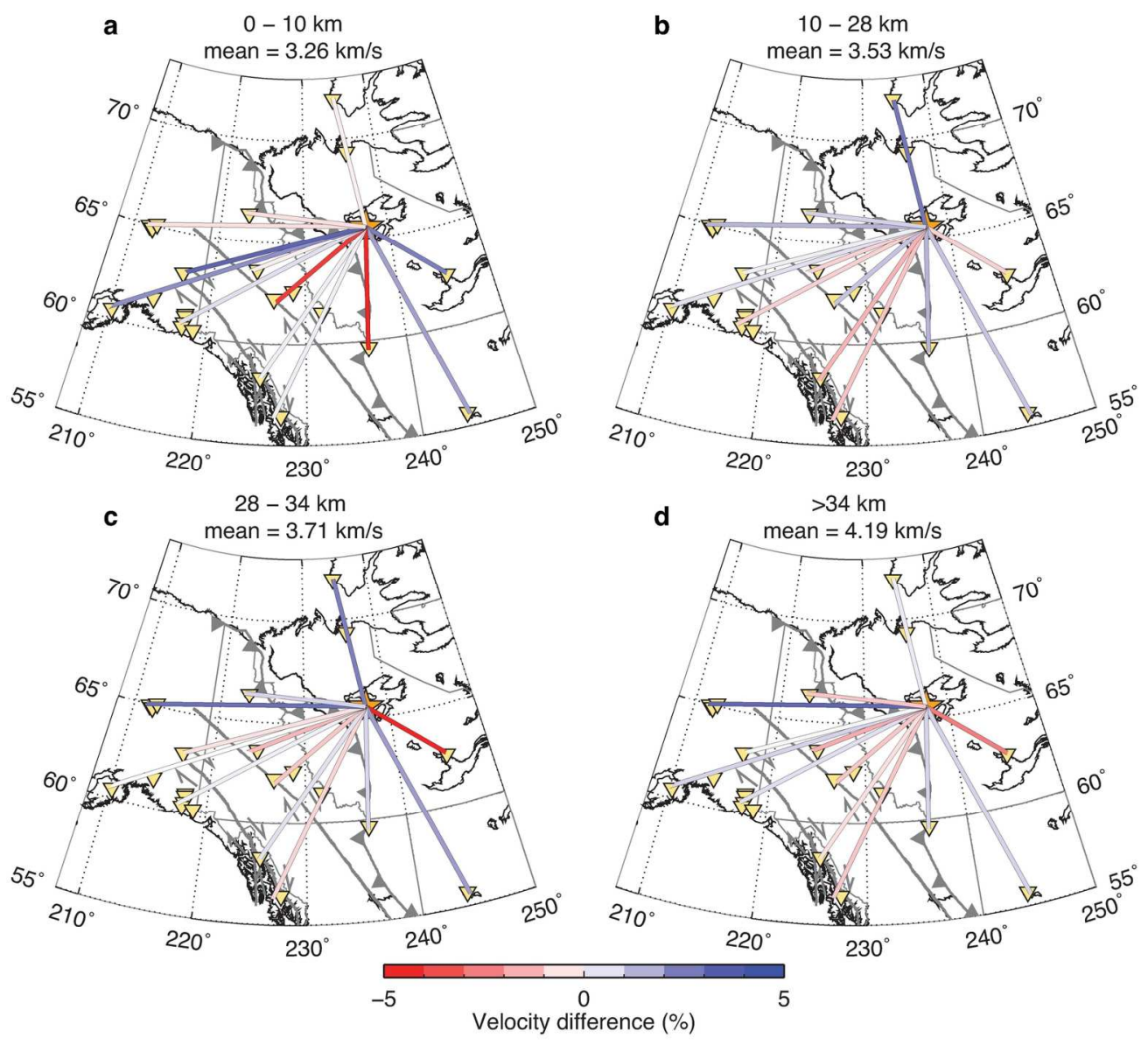

Figure 9

$163 \times 147 \mathrm{~mm}(300 \times 300 \mathrm{DPI})$ 


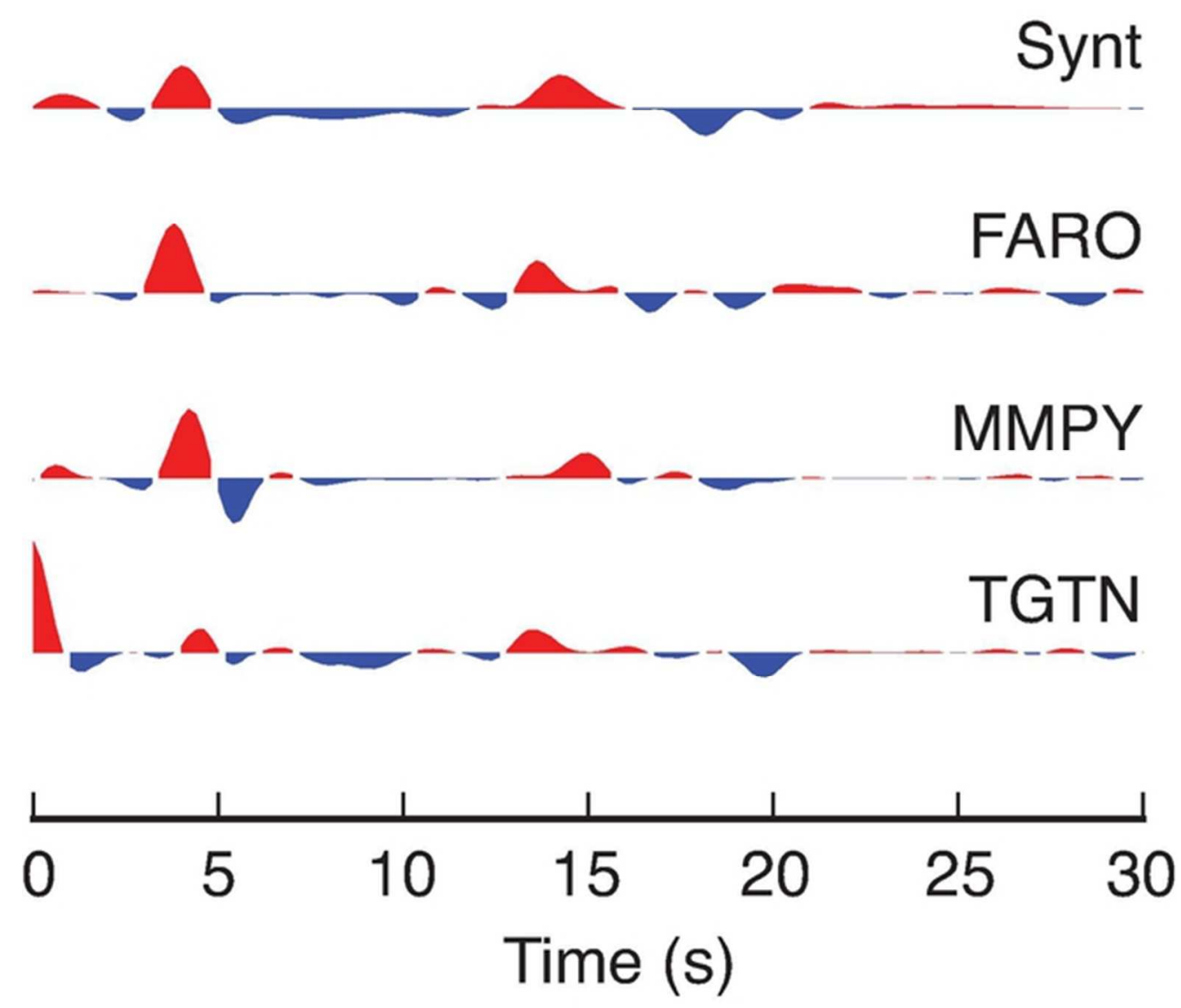

Figure 10

$55 \times 49 \mathrm{~mm}(300 \times 300 \mathrm{DPI})$ 


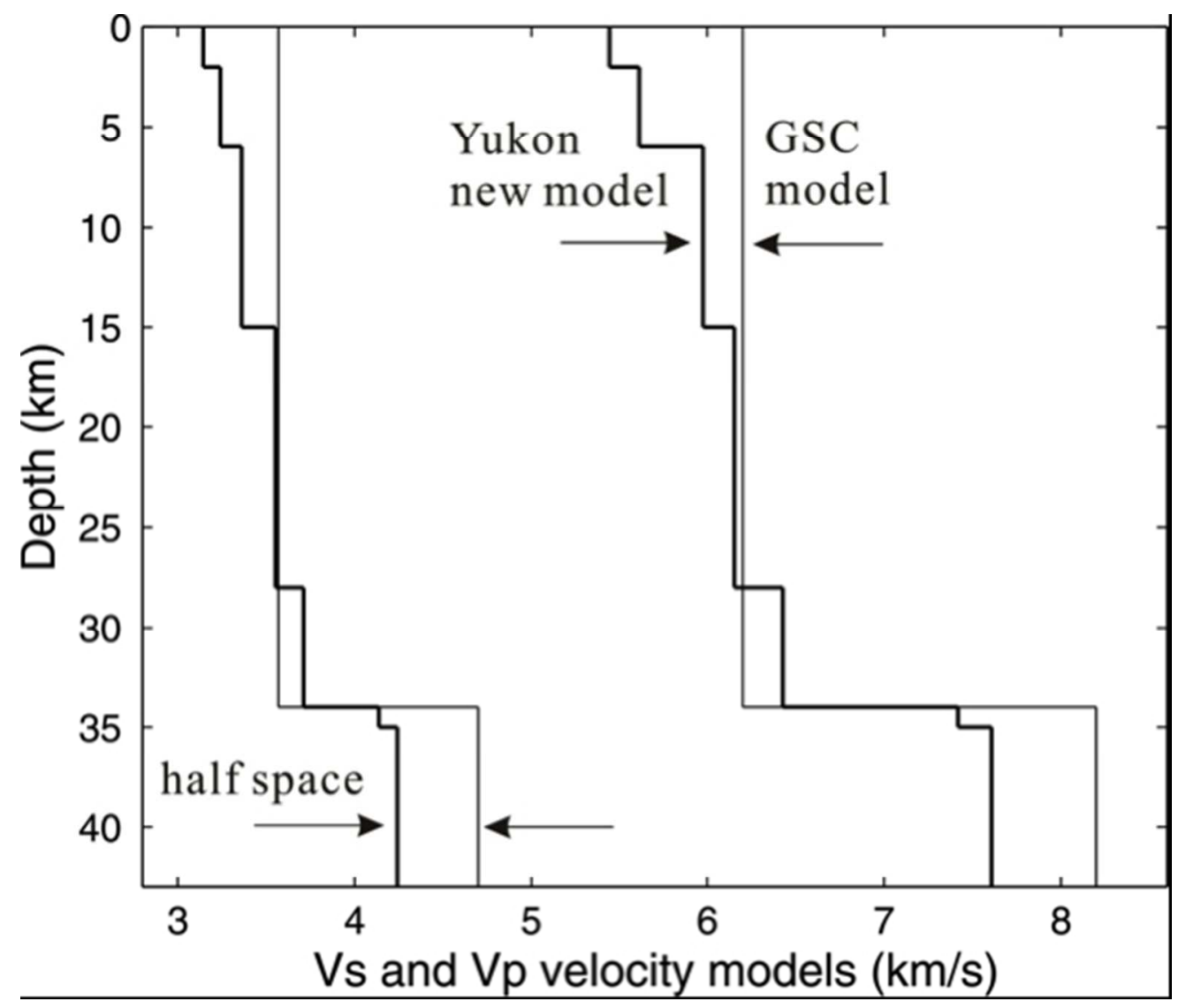

Figure 11 
Table S1. Shear-wave velocity models obtained at 13 azimuths. The first column $(\mathrm{H})$ is depth $(\mathrm{km})$; all other columns are shear-wave velocities $(\mathrm{km} / \mathrm{s})$ for each one of the 13 groups, indicated by the numbers in the second row. The rightmost column shows the average shear-wave velocity values. The depth value of 0 indicates a half space mantle.

\begin{tabular}{|ccccccccccccccc|}
\hline \multicolumn{10}{|c|}{ Shear-wave velocity } & $(\mathrm{km} / \mathrm{s})$ & models at 13 & azimuths (groups) & & \\
\hline $\mathrm{H}$ & 1 & 2 & 3 & 4 & 5 & 6 & 7 & 8 & 9 & 10 & 11 & 12 & 13 & Average \\
\hline 1 & 3.08 & 3.27 & 3.20 & 2.96 & 3.15 & 3.13 & 2.93 & 3.19 & 3.07 & 3.26 & 3.34 & 3.14 & 3.04 & 3.14 \\
2 & 3.11 & 3.29 & 3.22 & 2.98 & 3.17 & 3.15 & 2.96 & 3.21 & 3.09 & 3.28 & 3.35 & 3.16 & 3.07 & 3.15 \\
4 & 3.16 & 3.33 & 3.26 & 3.02 & 3.21 & 3.19 & 3.03 & 3.24 & 3.16 & 3.30 & 3.37 & 3.18 & 3.14 & 3.20 \\
6 & 3.28 & 3.37 & 3.35 & 3.12 & 3.29 & 3.30 & 3.19 & 3.29 & 3.31 & 3.33 & 3.37 & 3.23 & 3.29 & 3.29 \\
8 & 3.40 & 3.38 & 3.43 & 3.24 & 3.37 & 3.40 & 3.31 & 3.35 & 3.42 & 3.37 & 3.36 & 3.31 & 3.41 & 3.37 \\
10 & 3.48 & 3.38 & 3.48 & 3.35 & 3.42 & 3.46 & 3.38 & 3.39 & 3.46 & 3.42 & 3.38 & 3.39 & 3.46 & 3.42 \\
12 & 3.52 & 3.41 & 3.51 & 3.44 & 3.45 & 3.47 & 3.40 & 3.43 & 3.46 & 3.47 & 3.42 & 3.48 & 3.47 & 3.46 \\
14 & 3.56 & 3.46 & 3.53 & 3.51 & 3.47 & 3.46 & 3.42 & 3.47 & 3.46 & 3.52 & 3.48 & 3.55 & 3.48 & 3.49 \\
15 & 3.59 & 3.52 & 3.55 & 3.56 & 3.49 & 3.45 & 3.44 & 3.50 & 3.47 & 3.56 & 3.53 & 3.59 & 3.50 & 3.52 \\
17 & 3.62 & 3.57 & 3.57 & 3.60 & 3.51 & 3.45 & 3.46 & 3.52 & 3.49 & 3.60 & 3.59 & 3.63 & 3.53 & 3.55 \\
19 & 3.64 & 3.59 & 3.58 & 3.63 & 3.50 & 3.45 & 3.48 & 3.52 & 3.51 & 3.60 & 3.61 & 3.63 & 3.56 & 3.56 \\
21 & 3.65 & 3.58 & 3.58 & 3.63 & 3.50 & 3.45 & 3.49 & 3.52 & 3.52 & 3.58 & 3.60 & 3.61 & 3.59 & 3.56 \\
22 & 3.65 & 3.53 & 3.58 & 3.61 & 3.49 & 3.46 & 3.48 & 3.50 & 3.52 & 3.55 & 3.57 & 3.58 & 3.60 & 3.55 \\
24 & 3.70 & 3.53 & 3.62 & 3.64 & 3.53 & 3.53 & 3.53 & 3.54 & 3.57 & 3.57 & 3.59 & 3.60 & 3.65 & 3.59 \\
26 & 3.67 & 3.45 & 3.60 & 3.59 & 3.51 & 3.53 & 3.50 & 3.52 & 3.54 & 3.53 & 3.54 & 3.57 & 3.62 & 3.55 \\
28 & 3.63 & 3.37 & 3.57 & 3.55 & 3.48 & 3.52 & 3.47 & 3.49 & 3.49 & 3.49 & 3.49 & 3.56 & 3.58 & 3.51 \\
31 & 3.81 & 3.54 & 3.78 & 3.74 & 3.68 & 3.73 & 3.67 & 3.71 & 3.67 & 3.70 & 3.68 & 3.79 & 3.76 & 3.71 \\
34 & 3.78 & 3.54 & 3.77 & 3.74 & 3.68 & 3.72 & 3.67 & 3.73 & 3.65 & 3.72 & 3.69 & 3.82 & 3.72 & 3.71 \\
38 & 4.17 & 4.00 & 4.18 & 4.17 & 4.10 & 4.13 & 4.09 & 4.16 & 4.07 & 4.17 & 4.13 & 4.27 & 4.11 & 4.14 \\
0 & 4.25 & 4.17 & 4.27 & 4.29 & 4.20 & 4.21 & 4.20 & 4.27 & 4.19 & 4.29 & 4.26 & 4.37 & 4.19 & 4.24 \\
\hline
\end{tabular}



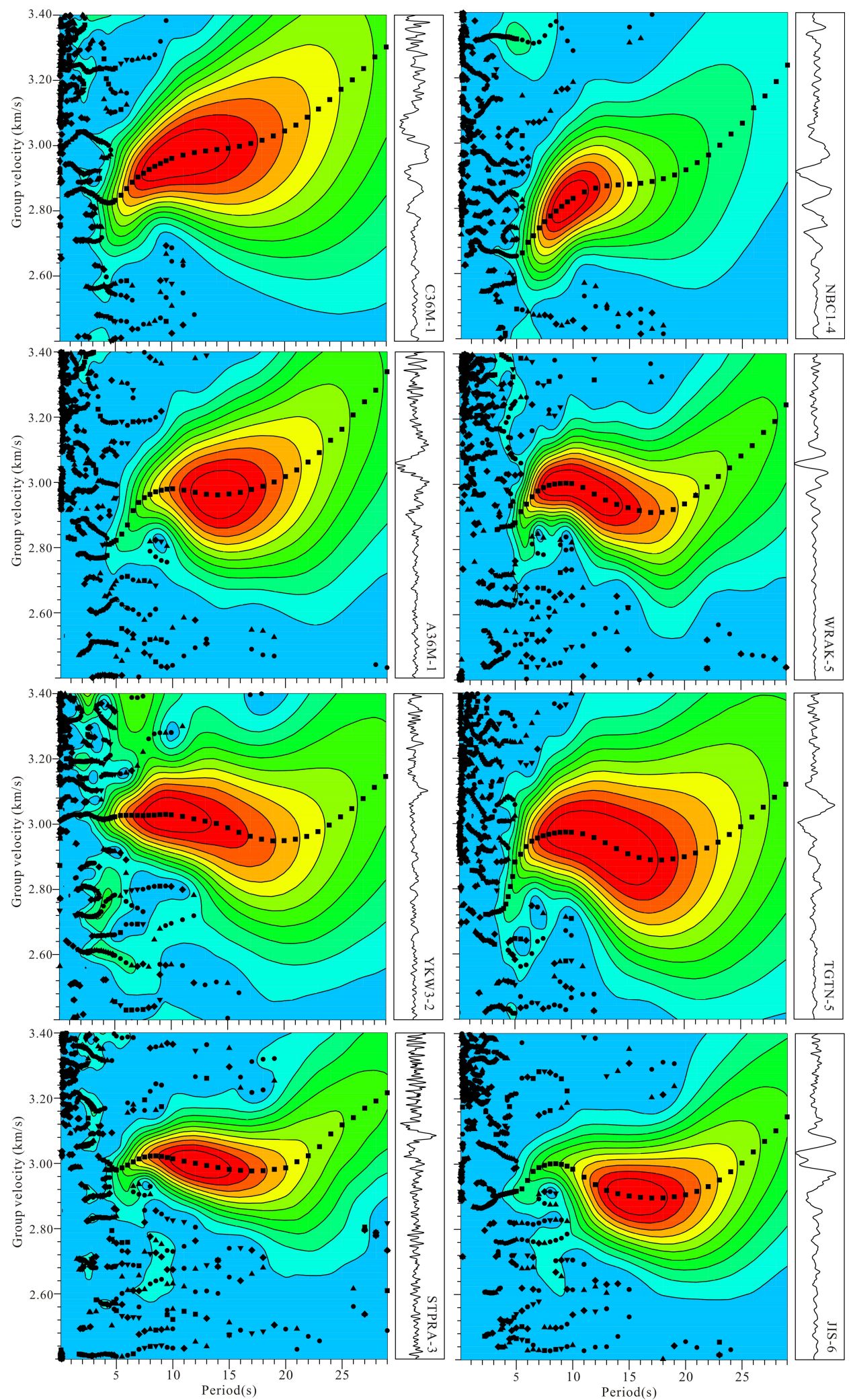

Figure S1. Observed Rayleigh wave dispersion curves at individual stations in groups 1 to 6 . The station name and the group number are printed at the bottom-right corner of each panel. 

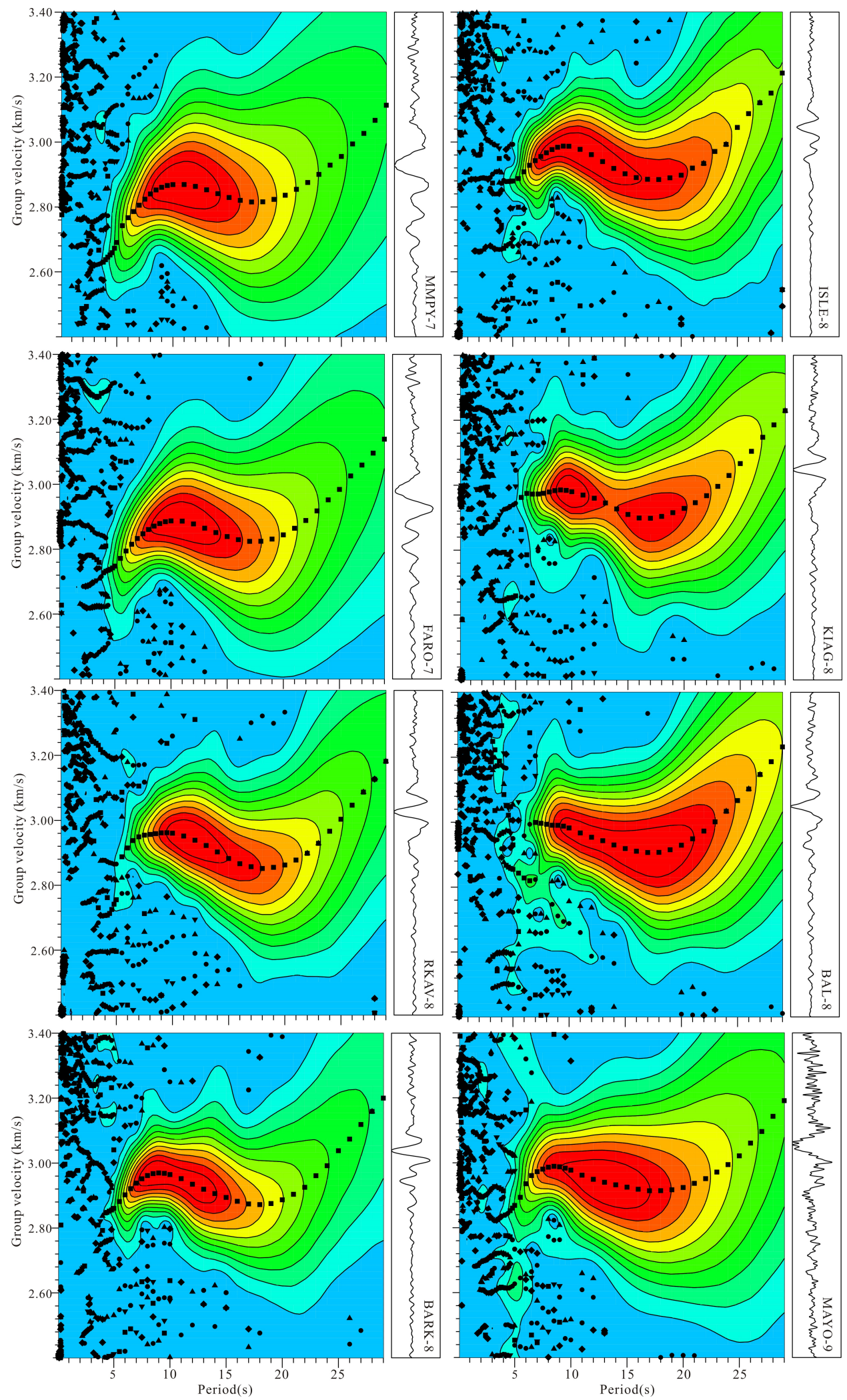

Figure S2. Observed Rayleigh wave dispersion curves at individual station in groups 7 to 9 . 


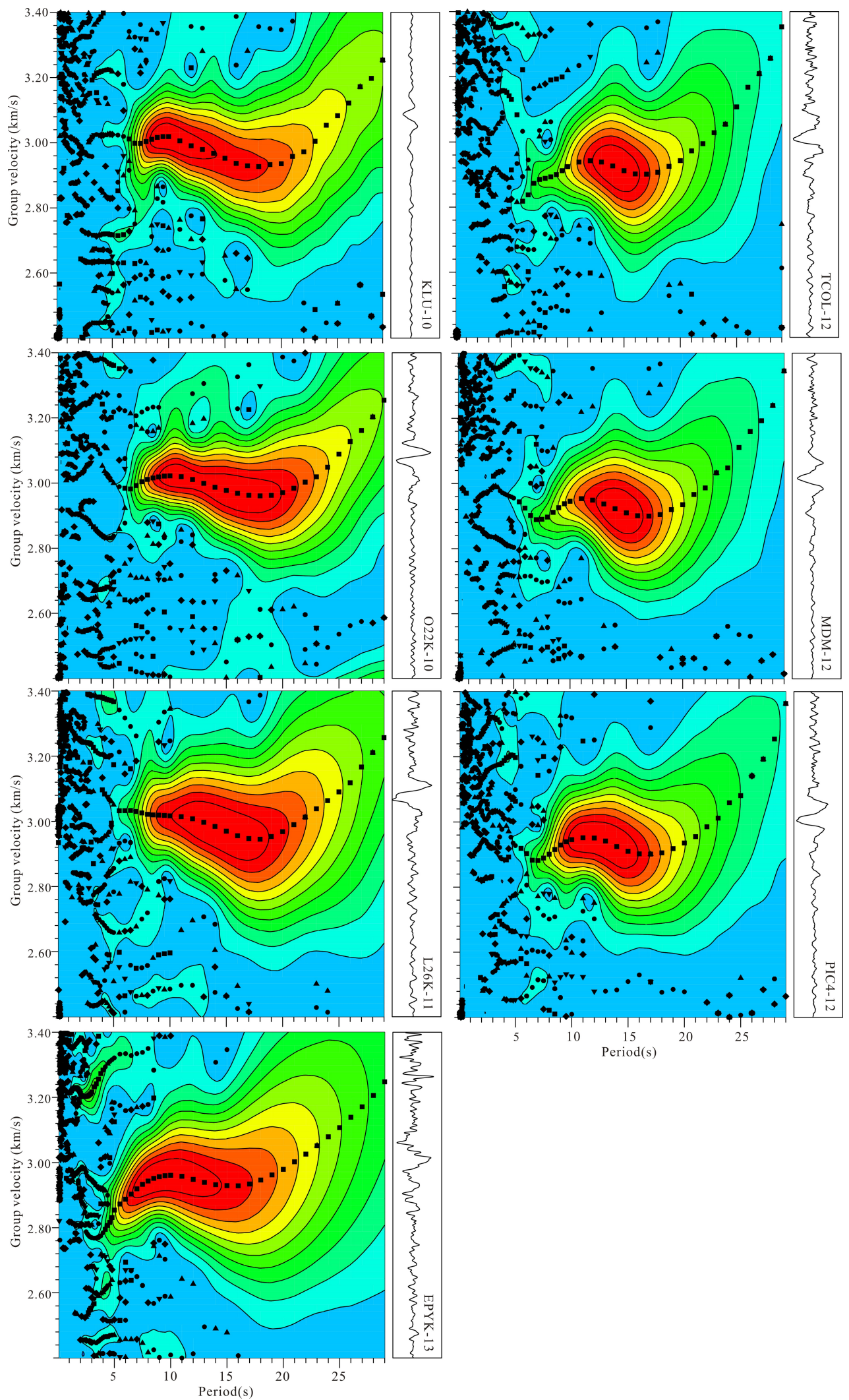

Figure S3. Observed Rayleigh wave dispersion curves at individual station in groups 10 to 13 . 
Table S1. Shear-wave velocity models obtained at 13 azimuths. The first column $(\mathrm{H})$ is depth $(\mathrm{km})$; all other columns are shear-wave velocities $(\mathrm{km} / \mathrm{s})$ for each one of the 13 groups, indicated by the numbers in the second row. The rightmost column shows the average shear-wave velocity values. The depth value of 0 indicates a half space mantle.

\begin{tabular}{|ccccccccccccccc|}
\hline \multicolumn{10}{|c|}{ Shear-wave velocity } & $(\mathrm{km} / \mathrm{s})$ & models at 13 & azimuths (groups) & & \\
\hline $\mathrm{H}$ & 1 & 2 & 3 & 4 & 5 & 6 & 7 & 8 & 9 & 10 & 11 & 12 & 13 & Average \\
\hline 1 & 3.08 & 3.27 & 3.20 & 2.96 & 3.15 & 3.13 & 2.93 & 3.19 & 3.07 & 3.26 & 3.34 & 3.14 & 3.04 & 3.14 \\
2 & 3.11 & 3.29 & 3.22 & 2.98 & 3.17 & 3.15 & 2.96 & 3.21 & 3.09 & 3.28 & 3.35 & 3.16 & 3.07 & 3.15 \\
4 & 3.16 & 3.33 & 3.26 & 3.02 & 3.21 & 3.19 & 3.03 & 3.24 & 3.16 & 3.30 & 3.37 & 3.18 & 3.14 & 3.20 \\
6 & 3.28 & 3.37 & 3.35 & 3.12 & 3.29 & 3.30 & 3.19 & 3.29 & 3.31 & 3.33 & 3.37 & 3.23 & 3.29 & 3.29 \\
8 & 3.40 & 3.38 & 3.43 & 3.24 & 3.37 & 3.40 & 3.31 & 3.35 & 3.42 & 3.37 & 3.36 & 3.31 & 3.41 & 3.37 \\
10 & 3.48 & 3.38 & 3.48 & 3.35 & 3.42 & 3.46 & 3.38 & 3.39 & 3.46 & 3.42 & 3.38 & 3.39 & 3.46 & 3.42 \\
12 & 3.52 & 3.41 & 3.51 & 3.44 & 3.45 & 3.47 & 3.40 & 3.43 & 3.46 & 3.47 & 3.42 & 3.48 & 3.47 & 3.46 \\
14 & 3.56 & 3.46 & 3.53 & 3.51 & 3.47 & 3.46 & 3.42 & 3.47 & 3.46 & 3.52 & 3.48 & 3.55 & 3.48 & 3.49 \\
15 & 3.59 & 3.52 & 3.55 & 3.56 & 3.49 & 3.45 & 3.44 & 3.50 & 3.47 & 3.56 & 3.53 & 3.59 & 3.50 & 3.52 \\
17 & 3.62 & 3.57 & 3.57 & 3.60 & 3.51 & 3.45 & 3.46 & 3.52 & 3.49 & 3.60 & 3.59 & 3.63 & 3.53 & 3.55 \\
19 & 3.64 & 3.59 & 3.58 & 3.63 & 3.50 & 3.45 & 3.48 & 3.52 & 3.51 & 3.60 & 3.61 & 3.63 & 3.56 & 3.56 \\
21 & 3.65 & 3.58 & 3.58 & 3.63 & 3.50 & 3.45 & 3.49 & 3.52 & 3.52 & 3.58 & 3.60 & 3.61 & 3.59 & 3.56 \\
22 & 3.65 & 3.53 & 3.58 & 3.61 & 3.49 & 3.46 & 3.48 & 3.50 & 3.52 & 3.55 & 3.57 & 3.58 & 3.60 & 3.55 \\
24 & 3.70 & 3.53 & 3.62 & 3.64 & 3.53 & 3.53 & 3.53 & 3.54 & 3.57 & 3.57 & 3.59 & 3.60 & 3.65 & 3.59 \\
26 & 3.67 & 3.45 & 3.60 & 3.59 & 3.51 & 3.53 & 3.50 & 3.52 & 3.54 & 3.53 & 3.54 & 3.57 & 3.62 & 3.55 \\
28 & 3.63 & 3.37 & 3.57 & 3.55 & 3.48 & 3.52 & 3.47 & 3.49 & 3.49 & 3.49 & 3.49 & 3.56 & 3.58 & 3.51 \\
31 & 3.81 & 3.54 & 3.78 & 3.74 & 3.68 & 3.73 & 3.67 & 3.71 & 3.67 & 3.70 & 3.68 & 3.79 & 3.76 & 3.71 \\
34 & 3.78 & 3.54 & 3.77 & 3.74 & 3.68 & 3.72 & 3.67 & 3.73 & 3.65 & 3.72 & 3.69 & 3.82 & 3.72 & 3.71 \\
38 & 4.17 & 4.00 & 4.18 & 4.17 & 4.10 & 4.13 & 4.09 & 4.16 & 4.07 & 4.17 & 4.13 & 4.27 & 4.11 & 4.14 \\
0 & 4.25 & 4.17 & 4.27 & 4.29 & 4.20 & 4.21 & 4.20 & 4.27 & 4.19 & 4.29 & 4.26 & 4.37 & 4.19 & 4.24 \\
\hline
\end{tabular}



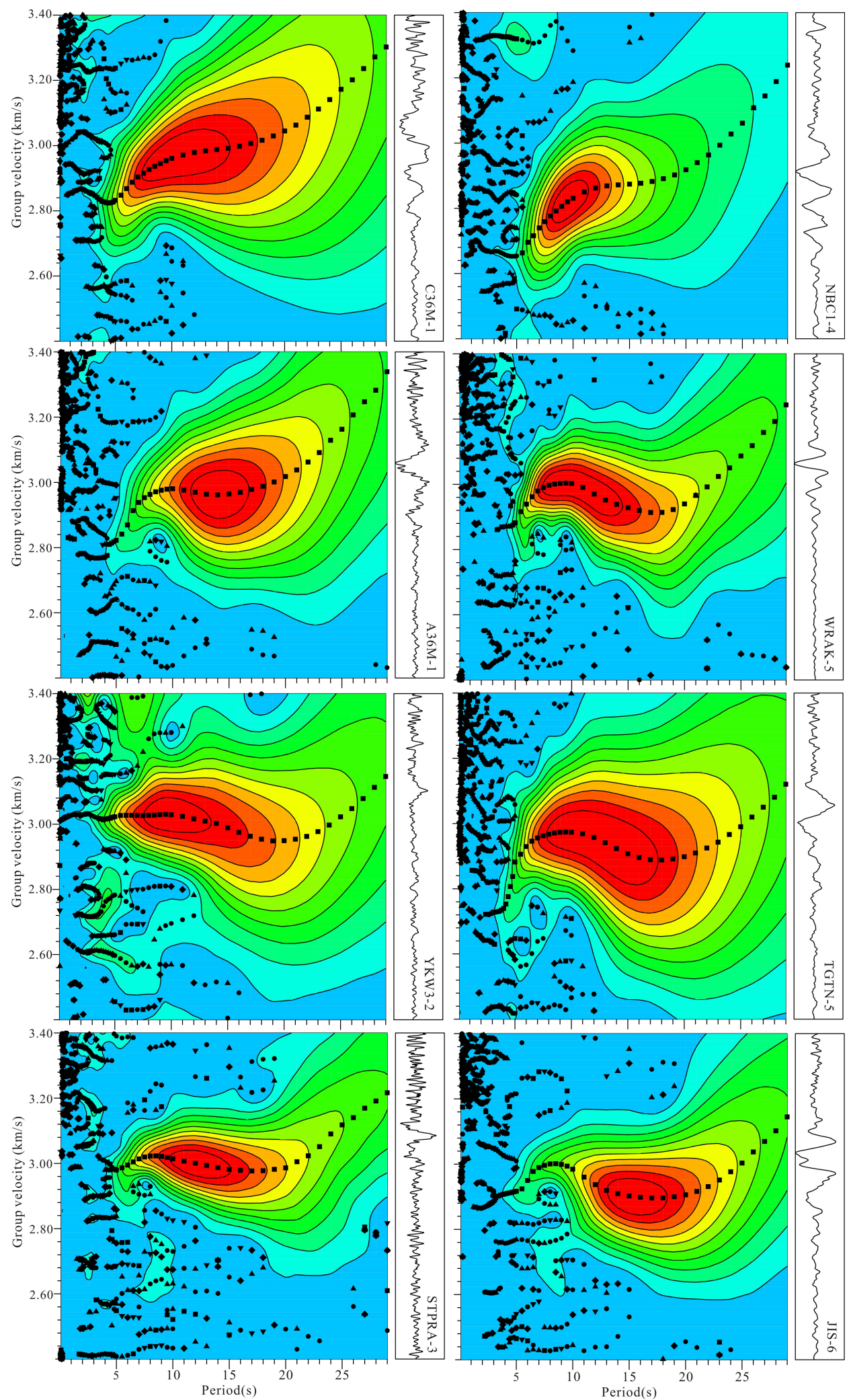

Figure S1. Observed Rayleigh wave dispersion curves at individual stations in groups 1 to 6 . The station name and the group number are printed at the bottom-right corner of each panel. 

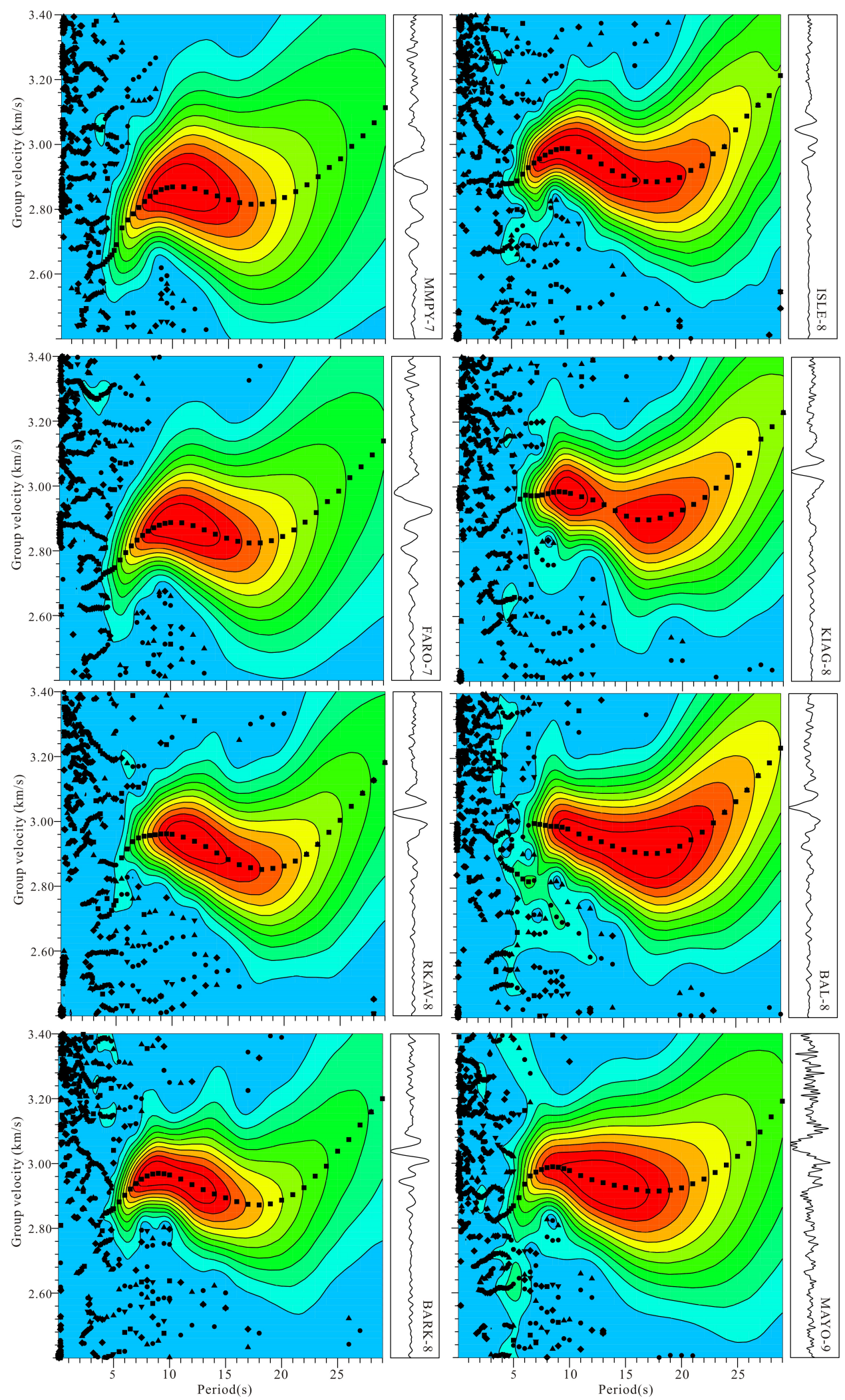

Figure S2. Observed Rayleigh wave dispersion curves at individual station in groups 7 to 9 . 


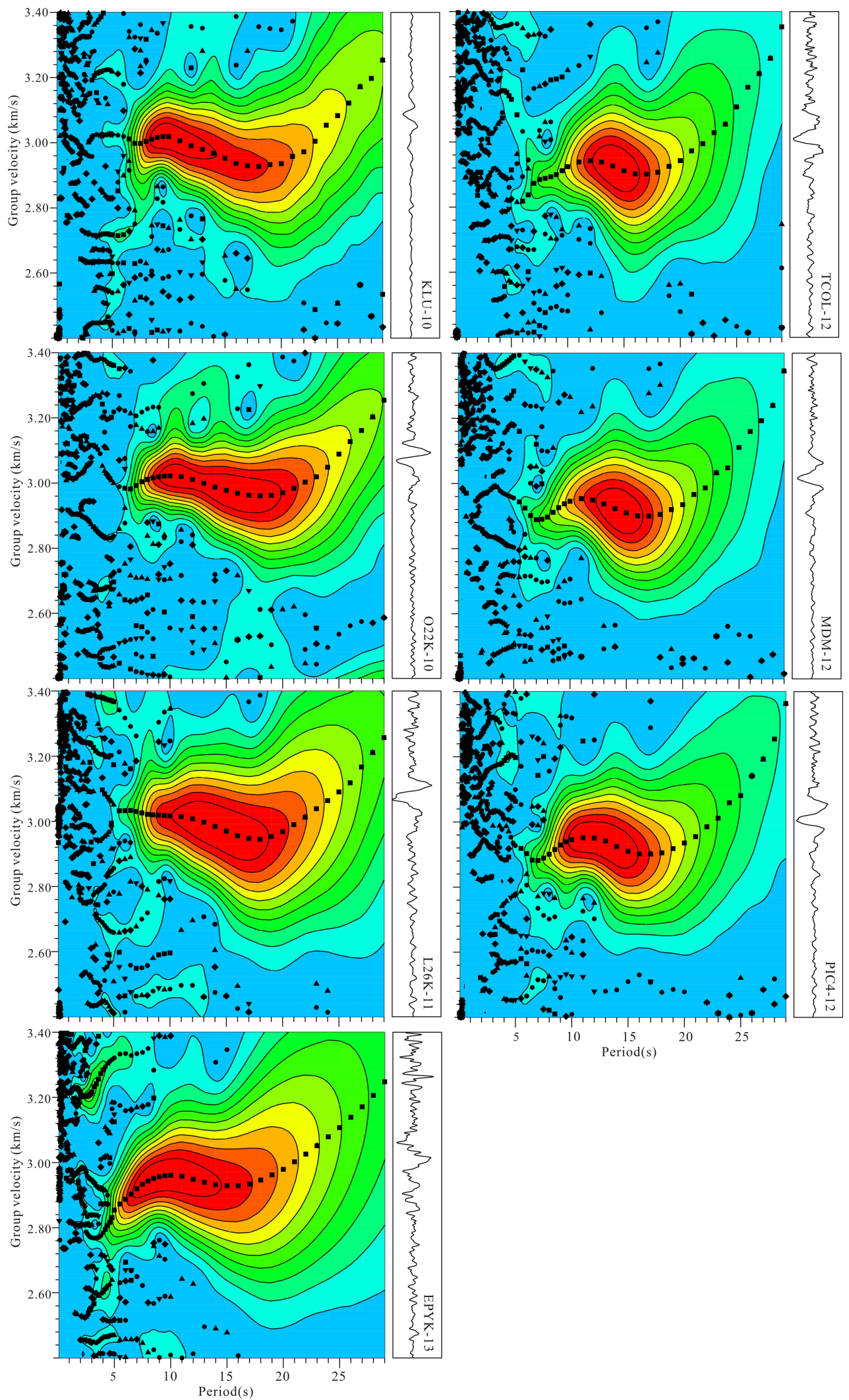

Figure S3. Observed Rayleigh wave dispersion curves at individual station in groups 10 to 13 . 